UNIVERSIDADE DE BRASÍLIA

INSTITUTO DE RELAÇÕES INTERNACIONAIS

IX CURSO DE ESPECIALIZAÇÃO EM RELAÇÕES INTERNACIONAIS

A EVOLUÇÃO DO REGIME INTERNACIONAL

DA PROPRIEDADE INTELECTUAL

Elisa de Ananias Fraga

Brasília, DF

2008 
ELISA DE ANANIAS FRAGA

\section{A EVOLUÇÃO DO REGIME INTERNACIONAL DA PROPRIEDADE INTELECTUAL}

Monografia apresentada como requisito parcial à obtenção do título de Especialista em Relações

Internacionais pela Universidade de Brasília

Orientadora: Prof ${ }^{a}$ Norma Breda dos Santos

\section{Brasília, DF}

2008 


\section{AGRADECIMENTOS}

Agradeço ao Márcio, à Cíntia, ao Carlos, à Sancia e ao Zeca, pelo aprendizado permanente; à Professora Norma, pelo incentivo; e ao Herlon, pela inspiração. 
'Where shall I begin, please your Majesty?' he asked. 'Begin at the beginning,' the King said, gravely, 'and go on till you come to the end: then stop.'

Lewis Carroll 
SUMÁRIO

Agradecimentos

Lista de siglas e abreviaturas

Lista de figuras

Lista de tabelas

Resumo

Introdução

1. OS REGIMES INTERNACIONAIS

1.1. A crítica de Susan Strange

2. A PROPRIEDADE INTELECTUAL

2.1. Os direitos de propriedade intelectual

3. A EVOLUÇÃO DA PROTEÇÃO À PROPRIEDADE INTELECTUAL

3.1. O período territorial

3.2. O período internacional

3.3. O período global

Considerações finais: a evolução do Regime Internacional da Propriedade Intelectual Referências bibliográficas 


\section{LISTA DE SIGLAS E ABREVIATURAS}

Acordo TRIPS - Acordo sobre Aspectos dos Direitos da Propriedade Intelectual relacionados ao Comércio

BIRPI - Bureaux Internationaux Réunis Pour la Protection de la Propriété Intelectuelle

CDB - Convenção sobre Diversidade Biológica

Convenção de Berna - Convenção de Berna para a Proteção de Obras Literárias e Artísticas

Conselho de TRIPS - Conselho dos Aspectos de Propriedade Intelectual relacionados ao Comércio

CUP/ Convenção de Paris - Convenção de Paris para a Proteção da Propriedade Industrial

DPIs - Direitos de Propriedade Intelectual

FTA - Free Trade Agreement

GATT - Acordo Geral de Tarifas e Comércio

OMPI - Organização Mundial da Propriedade Intelectual

OMC - Organização Mundial do Comércio

RIPI - Regime Internacional da Propriedade Intelectual

SPLT - Tratado Substantivo em Matéria de Patentes

UPOV - União Internacional para a Proteção de Obtenções Vegetais

WCT - Tratado da OMPI sobre Direitos de Autor

WPPT - Tratado sobre Interpretação ou Execução de Fonogramas 


\section{LISTA DE FIGURAS}

Figura 1: A área temática da propriedade intelectual 


\section{LISTA DE TABELAS}

Tabela 1: Acordos multilaterais sobre propriedade intelectual celebrados no período internacional, entre 1886 e 1995 


\section{RESUMO}

O objetivo do presente trabalho é analisar a evolução da proteção internacional da propriedade intelectual a partir da aplicação dos conceitos teóricos apresentados pelas escolas de regimes internacionais. Primeiramente, é feita uma introdução teórica a respeito das escolas de regimes internacionais, incluindo considerações críticas. Em seguida, a área temática da propriedade intelectual é delimitada, e é apresentada, em linhas gerais, a sustentação para a proteção aos direitos de propriedade intelectual. Após, é apresentado um histórico da proteção à propriedade intelectual, destacando três períodos: o período territorial, o período internacional e o período global. Finalmente, os conceitos teóricos introduzidos na primeira seção são aplicados ao desenvolvimento histórico da proteção à propriedade intelectual, de forma a delinear a evolução do Regime Internacional da Propriedade Intelectual. 


\section{INTRODUÇÃO}

O objetivo do presente trabalho é analisar a evolução da proteção internacional da propriedade intelectual a partir da aplicação dos conceitos teóricos apresentados pelas escolas de regimes internacionais. Dessa forma, é nossa intenção avaliar o desenvolvimento do Regime Internacional da Propriedade Intelectual (RIPI), desde o seu surgimento, no final do século XIX, até os tempos atuais. Merecerão destaque, de um lado, as circunstâncias que determinaram a criação do Regime e, de outro, as transformações resultantes da entrada em vigor do Acordo TRIPS, que expandiu as discussões sobre propriedade intelectual para o âmbito da Organização Mundial do Comércio (OMC).

Partiremos do conceito extraído da "definição consensual" elaborada por Krasner, que considera como regimes internacionais os "sets of implicit or explicit principles, norms, rules, and decision-making procedures around which actors' expectations converge in a given area of international relations" (KRASNER, 1995: 2). Na aplicação ao caso concreto, enfatizaremos a argumentação apresentada pelos adeptos da chamada escola neoliberal, que atribui ao interesse o papel de variável causal determinante na formação e o desenvolvimento dos regimes internacionais.

Quanto à área temática do regime internacional sob análise, optamos por considerar o conjunto dos direitos de propriedade intelectual, incluindo a propriedade industrial (patentes, marcas, desenhos industriais e indicações geográficas, entre outros); as obras protegidas por direitos de autor ou direitos conexos (obras literárias e artísticas e programas de computador); e a propriedade intelectual sui generis, que abarca bens intangíveis como 
as cultivares (novas variedades vegetais), as topografias de circuitos integrados e os conhecimentos tradicionais.

O trabalho está dividido em três seções, além das considerações finais. Na primeira seção é feita uma introdução teórica a respeito das escolas de regimes internacionais, incluindo considerações críticas. A segunda seção delimita a área temática da propriedade intelectual e apresenta, em linhas gerais, a sustentação para a proteção aos direitos de propriedade intelectual. A terceira seção apresenta um histórico da proteção à propriedade intelectual, destacando três períodos: o período territorial, o período internacional e o período global.

Finalmente, nas considerações finais os conceitos teóricos introduzidos na primeira seção são aplicados ao desenvolvimento histórico da proteção à propriedade intelectual, tal como descrita na terceira seção, de forma a delinear a evolução do Regime Internacional da Propriedade Intelectual. 


\section{OS REGIMES INTERNACIONAIS}

O estudo dos regimes internacionais surgiu na década de 1970 e atingiu enorme popularidade entre os analistas de relações internacionais desde então (YOUNG, 1999: 189). Não se trata de uma teoria única, mas de um conjunto de escolas de pensamento que compartilham um núcleo mais ou menos homogêneo de pressuposições sobre o papel das instituições na cooperação internacional. As diferentes abordagens apresentam uma notável pluralidade metodológica e epistemológica, a que se tem atribuído tanto o vigor quanto a vulnerabilidade do enfoque (YOUNG, 1999: 204).

A controvérsia que permeia as abordagens teóricas dos regimes internacionais revela-se já a partir do debate em torno da conceituação dos regimes internacionais. A definição dita consensual foi elaborada por Stephen Krasner no início da década de 1980, e caracteriza os regimes como

\footnotetext{
"sets of implicit or explicit principles, norms, rules, and decision-making procedures around which actors' expectations converge in a given area of international relations. Principles are beliefs of fact, causations, and rectitude. Norms are standards of behaviour defined in terms of rights and obligations. Rules are specific prescriptions or proscriptions for action. Decision-making procedures are prevailing practices for making and implementing collective choice." (KRASNER, 1995: 2).
}

No entanto, essa formulação não é unânime; ao contrário, ela vem sendo criticada por muitos estudiosos dos regimes internacionais. É o caso de Oran Young, que a considera excessivamente complexa, além de vaga quanto à diferenciação entre princípios, normas, regras e procedimentos, o que, conclui, comprometeria a sua adequada aplicação a situações reais. Robert Keohane está entre os que propuseram, como alternativa, uma 
definição mais precisa: para ele, regimes devem ser concebidos como "institutions with explicit rules, agreed upon by governments, that pertain to particular sets of issues in international relations" (apud HASENCLEVER, MAYER e RITTBERGER, 1997: 11-12).

A despeito do debate, a grande maioria dos estudiosos de regimes inclina-se a adotar concepções que se aproximam bastante da "definição consensual", sendo, dessa forma, compatíveis com a formulação de Krasner. Assim é que encontramos o mesmo Keohane, agora em co-autoria com Nye, referindo-se em outra oportunidade a "regimes of norms, rules, and institutions that govern a surprisingly large number of issues in world politics" (MIMEO: 20); ou Young, conceituando regimes como "sets of rules, decisionmaking procedures and/or programs that give rise to social practices, assign roles to the participants in these practices, and govern their interactions" (1999: 5).

O debate relativo à definição do conceito de regimes internacionais reflete os diferentes tratamentos teóricos dados ao tema. Nesse sentido, podem ser apontadas três diferentes escolas de pensamento, classificadas em função do peso dado às diferentes variáveis intervenientes na formação e desenvolvimento dos regimes: a realista, a neoliberal e a cognitivista (HASENCLEVER, MAYER e RITTBERGER, 1997: 3-6), que correspondem respectivamente, na disposição de Krasner, às abordagens estrutural convencional, estrutural modificada e grotiana/liberal (KRASNER, 1995: 5-10). A primeira elege como variável explicativa causal o poder; a segunda, os interesses; e a terceira, o conhecimento. 
A escola realista (ou estrutural convencional) parte do entendimento de que os Estados agem como atores racionais em busca de ganhos relativos de poder. Por esta visão, a formação e a permanência dos regimes internacionais fica comprometida, na medida em que os membros menos beneficiados - que sempre existirão, já que distribuição desigual de poder entre os atores impede que os benefícios sejam igualmente compartidos - tenderão a rejeitá-los.

Já a escola neoliberal (ou estrutural modificada) destaca que os regimes internacionais surgem para auxiliar os Estados a conquistarem interesses comuns. Cada Estado age como um ator egoísta e racional, atraído por possíveis ganhos absolutos (em decorrência da redução dos custos transacionais, por exemplo). Por esta perspectiva, desde que gerem benefícios a todos os seus membros (ainda que de forma desigual), os regimes tenderão a permanecer.

A terceira e última escola é a cognitivista (ou grotiana/liberal), que elege como variável explicativa causal não o poder ou o interesse dos Estados, mas o conhecimento. Esta escola pode ser subdividida em duas "correntes": a dos cognitivistas fracos, que acrescenta à perspectiva neoliberal a teoria da formação das preferências; e a dos cognitivistas fortes, que propõe uma reestruturação completa das teorias racionalistas, destacando, a partir de um enfoque sociológico, a influência dos regimes na conformação das identidades dos atores internacionais.

Ao lado dessas três escolas, Hasenclever, Mayer e Rittberger identificam três abordagens distintas (HASENCLEVER, MAYER e RITTBERGER, 1997: 14-21). A 
primeira delas é a comportamental (ou behaviourista), que defende que as regras que constituem um regime devem necessariamente moldar comportamentos, isto é, devem ter eficácia. Não é necessário que as regras tenham sido formalmente declaradas, admitindo-se, portanto, a existência de regimes implícitos.

Em oposição, o segundo enfoque - denominado formal - caracteriza os regimes internacionais como compostos por regras enunciadas de maneira explícita (regimes implícitos não são admitidos), sejam essas regras eficazes ou não.

Por fim, a terceira abordagem é a cognitiva, que, afastando-se da tradição epistemológica positivista de separação entre sujeito e objeto, assume que os regimes são instituições ontologicamente intersubjetivas, constituídas a partir de entendimentos compartilhados sobre comportamentos sociais desejáveis e aceitáveis.

As escolas realista e neoliberal tendem a adotar uma abordagem formal (regimes são sempre explícitos, ainda que não totalmente eficazes) ou, mais raramente, uma abordagem comportamental (regimes podem ser implícitos, mas suas regras devem ser sempre obedecidas). Já os adeptos da escola cognitivista tendem a adotar a perspectiva cognitiva (regimes como construções intersubjetivas). Dentre todas as abordagens, a formal tem sido a mais utilizada. Como destacado por Hasenclever, Mayer e Rittberger, essa preferência tem razões acima de tudo pragmáticas - a investigação de um regime é facilitada em grande medida quando os elementos normativos que o compõem são explicitamente formulados e, em conseqüência, objetivamente verificáveis (HASENCLEVER, MAYER e RITTBERGER, 1997: 21). 
Contudo, as fronteiras entre as diversas escolas e abordagens são bastante fluidas. As mais das vezes, os estudiosos de regimes internacionais tendem a adotar elementos das diversas orientações, o que torna difícil a tarefa de classificar um determinado autor como integrante desta ou daquela corrente. Essas classificações, portanto, assumem relevância primordialmente didática. Elas ilustram, acima de tudo, a heterogeneidade dos tratamentos que compõem o conjunto de estudos dos regimes internacionais.

Independentemente da escola ou abordagem teórica, os regimes não devem ser confundidos com as organizações internacionais (YOUNG, 1999, p. 7; HASENCLEVER, MAYER e RITTBERGER, 1997, pp. 10-11). Trata-se, em ambos os casos, de instituições internacionais, mas há especificidades que os diferenciam. Os regimes não detêm, como as organizações internacionais, personalidade jurídica própria; em outras palavras, eles não podem ser sujeitos de direitos e obrigações. Bem assim, enquanto os regimes cobrem uma área temática específica, as organizações internacionais podem estender-se por diversas issue-areas. Não obstante, é possível que uma (ou mais) organização(ões) internacional(is) sirva $(m)$ de apoio a um determinado regime internacional.

Oran Young identifica três tipos de ordem que condicionam a formação dos regimes internacionais: a espontânea, a negociada e a imposta (YOUNG, 1995: 98-101). As instituições que emergem como ordens espontâneas são assentadas na ausência de coordenação consciente e de consentimento explícito dos envolvidos. Normalmente, elas envolvem baixos custos transacionais e poucas restrições formais à liberdade de seus participantes. 
As ordens negociadas, em contraste, caracterizam-se pelo esforço consciente dos sujeitos no sentido de concordarem com as questões centrais envolvidas e manifestarem explicitamente o seu consentimento. São regimes revestidos de maior formalidade, largamente encontrados nas relações internacionais. Muitos autores, em especial aqueles que aderem à escola neoliberal, tendem a considerar como regimes internacionais apenas aquelas instituições que surgem a partir de ordens negociadas.

Já as ordens impostas são implementadas deliberadamente pelas potências dominantes (que podem estar reunidas em um consórcio), prescindindo do consentimento dos atores subordinados e, via de regra, de qualquer expressão formal. Há dois tipos de regimes impostos: aquele em que a potência articula clara e explicitamente os arranjos institucionais, compelindo os demais atores a segui-los; e aquele em que o ator dominante logra promover os arranjos institucionais favoráveis através da liderança e da manipulação de incentivos.

A tendência é que as ordens impostas sejam menos eficientes que as demais, já que elas têm como objetivo atender apenas aos interesses hegemônicos e, além disso, sua manutenção tende a tornar-se excessivamente dispendiosa, salvo quando o poder central logra conquistar a legitimação dos atores subordinados. Tal legitimação seria possível, argumenta Young, a partir do cultivo de "hábitos de obediência". Esses componentes ideacionais e cognitivos, aliados aos estruturais, com o tempo tornariam dispensável o uso da força para a manutenção do regime (YOUNG, 1995: 101). 
Independentemente da ordem em que emirjam, as transformações nos regimes podem decorrer das suas contradições internas, de mudanças na distribuição internacional de poder e/ou de forças exógenas (YOUNG, 1995: 113), e poderão se manifestar por alterações nos diversos elementos normativos do regime internacional - princípios, normas, regras e procedimentos decisórios.

Para Krasner, os princípios e normas constituem o cerne dos regimes internacionais: alterações nesses elementos transformam os próprios regimes, extinguindo-os ou dando lugar a novas instituições. Meras mudanças nas regras e nos procedimentos, em contraste, representam apenas adaptações dentro dos regimes (KRASNER, 1995: 3-4).

No primeiro caso (mudanças nos princípios e normas), trata-se de um fenômeno revolucionário, via de regra atribuído a mudanças na distribuição de poder político entre os atores. Embora admita que alterações significativas na estrutura de poder afetem as três ordens acima expostas (espontânea, negociada e imposta), Young sublinha que elas tendem a ser especialmente letais aos regimes impostos: "It is perhaps obvious that imposed orders are unlikely to survive for long following major declines in the effective power of the dominat actor or actors" (YOUNG, 1995: 108).

As alterações revolucionárias dos regimes também podem ser ocasionadas por transformações na superestrutura (normas e princípios difusos e gerais), na medida em que tais transformações alterem substantivamente a sub-estrutura (os regimes em si: 
condicionamento de comportamentos em issue-areas específicas) ${ }^{1}$, modificando seu núcleo normativo.

$\mathrm{Na}$ segunda hipótese (mudanças nas regras e procedimentos), lidamos com um fenômeno meramente evolucionário ${ }^{2}$, geralmente decorrente da adaptação a novas realidades sociais, como a emergência de novas tecnologias. Contudo, é possível que o regime não logre se adaptar às mudanças sociais - especialmente quando se tratar de um regime espontâneo (YOUNG, 1995: 105-106); ou que os novos conhecimentos resultem numa ruptura paradigmática na superestrutura. Nesses casos, o regime como tal tenderá a perder vigor, especialmente nos planos cognitivo e comportamental; a conseqüência poderá ser a sua extinção ou substituição por um novo arranjo institucional.

A possibilidade de distinguir as mudanças no regime das mudanças do regime, tornada possível a partir da diferenciação dos elementos normativos dos regimes internacionais (princípios, normas, regras, procedimentos de tomada de decisão), tem sido apontada como uma das vantagens da "definição consensual" de Krasner (HASENCLEVER, MAYER e RITTBERGER, 1996: 180). Na medida em que um dos objetivos deste estudo é identificar as transformações do regime internacional da propriedade intelectual, adotaremos esta definição - que, de resto, parece-nos adequada também para uma descrição apropriada dos elementos normativos que compõem o regime internacional em questão.

\footnotetext{
${ }^{1}$ Retomamos a distinção de Hopkins e Puchala, entre superestrutura e sub-estrutura, mencionada por Krasner (KRASNER, 1995: 17).

${ }^{2}$ Krasner atribui a Hopkins e Puchala o conceito de mudança evolucionária, contraposta à revolucionária.
} 
Bem assim, por acreditar que a variável causal determinante para este regime tende a ser o interesse, na maior parte das vezes a análise seguirá uma orientação neoliberal (ou estrutural modificada). Como na maior parte dos estudos que seguem essas duas orientações, o enfoque adotado será o formal: trataremos de um regime explícito, de eficácia variável. Finalmente, exploraremos tanto os conceitos de ordem imposta como a ordem negociada, embora com maior destaque para esta última.

\subsection{Crítica de Susan Strange}

Antes de encerrarmos esta introdução teórica, apresentaremos os cinco argumentos principais introduzidos por Susan Strange (1982: 479-493) como questionamentos à validade e à utilidade do conceito de regimes internacionais para os estudos de economia política internacional ou política mundial. Como tentaremos demonstrar, a argumentação apresentada por Strange, embora parcialmente pertinente, não afasta a conveniência de adotarmos a abordagem dos regimes internacionais neste estudo.

O primeiro argumento é que o estudo dos regimes internacionais consiste em um modismo acadêmico norte-americano, que reflete uma percepção subjetiva, equivocada do ponto de vista da autora, da erosão do poder hegemônico dos Estados Unidos e dos distintos papéis políticos representados pelas organizações internacionais na década de 1970, não representando, portanto, uma contribuição relevante em uma perspectiva de longo prazo. 
Esse argumento parece haver perdido a sua força com o fato de ainda hoje, passados trinta anos da publicação dos primeiros estudos, as diferentes abordagens de regimes internacionais servirem de orientação a investigações sobre a cooperação internacional em áreas temáticas específicas.

Como segundo argumento, Strange assevera que o conceito de regime internacional é impreciso, abrangendo desde concepções mais restritas, que compreendem apenas arranjos internacionais acordados, explícitos ou implícitos, até concepções mais amplas, que abrangem qualquer estrutura de poder que seja relativamente estável e que influencie a ordem internacional.

Reconhecemos o risco de imprecisão conceitual nos estudos sobre regimes internacionais. Neste trabalho, tentaremos afastá-lo com a adoção, como já mencionado anteriormente, da "definição consensual" de Krasner.

$\mathrm{O}$ terceiro argumento consiste em que as análises baseadas nos regimes internacionais não são imparciais, já que podem superdimensionar a previsibilidade e a ordem presentes no sistema internacional, além de equivocadamente partirem da idéia de que a proliferação de regimes é necessariamente positiva.

Entendemos que qualquer perspectiva teórica adotada na área das ciências sociais será parcial. Tendo isso em conta, se é verdade que alguns estudos de regimes internacionais tendem a valorizar de maneira excessiva esses arranjos e, em sentido mais amplo, a ordem internacional, a descrição que faremos do regime internacional da 
propriedade intelectual não partirá da avaliação de que a existência de cooperação internacional nessa área é necessariamente positiva. Ao contrário, restará demonstrado (embora esse não seja um objetivo central deste trabalho) que o valor atribuído ao regime internacional da propriedade intelectual variará de acordo com os interesses dos diferentes atores internacionais envolvidos: enquanto os países com maior desenvolvimento e produção de bens intelectuais tenderão a apoiar o fortalecimento do regime internacional em questão, os demais países tenderão a considerá-lo como negativo.

O quarto argumento considera que, embora os arranjos internacionais sejam dinâmicos, os estudos de regimes internacionais partem de uma perspectiva estática, que tende a desconsiderar fatores que condicionam as posições dos governos nacionais e, em conseqüência, geram mudanças nesses arranjos.

Como esclarecido supra, um dos focos de nossa análise será as mudanças no e/ou do regime internacional da propriedade intelectual. Dessa forma, buscaremos abordar prioritariamente não os aspectos estáticos do regime internacional em estudo, mas, de forma especial, o seu processo de transformação ao longo do tempo.

Finalmente, o quinto argumento de Strange aponta que o estudo dos regimes internacionais seguem um paradigma estadocêntrico que tende a limitar a percepção da realidade, na medida em que não abrange aquelas áreas que não são cobertas por acordos entre entes estatais. 
Como veremos na próxima seção, a proteção à propriedade intelectual dá-se pela concessão ou pelo reconhecimento, pelo Estado, de direitos de propriedade sobre os bens intelectuais. Por outro lado, os arranjos internacionais que constituem o regime internacional da propriedade intelectual são instrumentos acordados entre Estados: em outras palavras, trata-se de uma área temática coberta por acordos entre entes estatais. Dessa forma, entendemos válida uma abordagem que privilegie o papel dos Estados na instituição e no desenvolvimento do regime internacional em análise, sem, contudo, desconsiderar a atuação dos atores não-estatais. 


\section{A PROPRIEDADE INTELECTUAL}

Tendo sido introduzido o arcabouço teórico que será utilizado, cabe agora delimitar o que será considerado neste estudo como o regime internacional da propriedade intelectual. Antes de tudo, é importante conceituar a propriedade intelectual e, dessa forma, demarcar com maior precisão a área temática do regime internacional em questão.

A maior parte das definições, em lugar de identificar os atributos essenciais da propriedade intelectual, simplesmente enumera as diferentes categorias de direitos de propriedade intelectual ou ainda, as matérias protegidas por esses direitos (DRAHOS, 1998: 1). Essa limitação ocorre principalmente em textos normativos, como, por exemplo, a Convenção que estabelece a Organização Mundial da Propriedade Intelectual (OMPI), de 1967, e o Acordo sobre Aspectos dos Direitos da Propriedade Intelectual relacionados ao Comércio (Acordo TRIPS), de $1994^{3}$.

Entretanto, a doutrina oferece algumas definições da propriedade intelectual, que é conceituada ora como "o[s] produto[s] da atividade criadora" (BASSO, 2000: 54), ora como "a form of knowledge which societies have decided can be assigned specific property rights” (CIPR, 2002: 11). A partir dessas definições, é possível considerar como

\footnotetext{
${ }^{3}$ Convenção que estabelece a Organização Mundial da Propriedade Intelectual (OMPI), Artigo 2 (viii):

"'intellectual property' shall include the rights relating to: literary, artistic and scientific works; performances of performing artists, phonograms, and broadcasts; inventions in all fields of human endeavor; scientific discoveries; industrial designs; trademarks, service marks, and commercial names and designations; protection against unfair competition; and all other rights resulting from intellectual activity in the industrial, scientific, literary or artistic fields."

Acordo TRIPS, Artigo 1.2: "Para os fins deste acordo, o termo "propriedade intelectual" refere-se a todas as categorias de propriedade intelectual que são objeto das Seções 1 a 7 da Parte II." (As seções 1 a 7 referem-se às seguintes categorias: direitos de autor e direitos conexos, marcas, indicações geográficas, desenhos industriais, patentes, topografia de circuitos integrados, proteção de informação confidencial e controle de práticas de concorrência desleal em contratos de licenças)
} 
propriedade intelectual o conjunto de ativos imateriais que resultam da inteligência ou da inventividade humana e sobre os quais recai um direito de propriedade.

Há dois elementos nessa definição que merecem destaque. Em primeiro lugar, a propriedade intelectual não corresponde à atividade criadora em si, mas sim aos bens intangíveis dela resultantes, vale dizer, às obras e invenções que são o fruto dessa atividade. Em segundo lugar, nem todos os bens intangíveis que resultam da atividade criadora devem ser considerados propriedade intelectual, mas apenas aqueles protegidos pelo Estado, a partir da concessão ou do reconhecimento de um direito de propriedade. Trata-se, portanto, da "idéia expressa, exteriorizada, ou seja, o produto da atividade criadora", que, por sua vez, seja objeto de proteção pelo Direito (BASSO, 2000: 54).

É possível reconhecer nesse conjunto de ativos imateriais três subgrupos: o subgrupo da propriedade industrial (patentes, marcas, desenhos industriais e indicações geográficas, entre outros); o subgrupo das obras protegidas por direitos de autor ou direitos $\operatorname{conexos}^{4}$ (obras literárias e artísticas e programas de computador); e o subgrupo da propriedade intelectual sui generis, que abarca bens intangíveis como as cultivares (novas variedades vegetais), as topografias de circuitos integrados e os conhecimentos tradicionais ${ }^{5}$. Esses três subgrupos apresentam, cada um deles, as suas particularidades;

\footnotetext{
${ }^{4}$ No passado, alguns consideravam "propriedade intelectual" apenas as obras artísticas e literárias protegidas por direitos de autor e direitos conexos, excluindo do conceito a "propriedade industrial". No entanto, a partir da criação da OMPI, e definitivamente após o Acordo TRIPS, consolidou-se o conceito de propriedade intelectual que abarca todos os bens intelectuais, incluindo aqueles com aplicação industrial.

${ }^{5}$ A proteção aos conhecimentos tradicionais é recente se comparada à das espécies clássicas de propriedade intelectual. Ela é também bastante controversa. Enquanto alguns países optaram por estabelecer sistemas sui generis de propriedade intelectual (é o caso do Brasil, que instituiu proteção à parcela desses conhecimentos associada ao patrimônio genético nacional em 2000, com a edição da Medida Provisória $\mathrm{n}^{\circ} 2.186$, ainda em vigor), outros elegeram proteger tais conhecimentos por meio dos instrumentos já tradicionais, como patentes,
} 
além disso, dentro de cada subgrupo, cada uma das diferentes espécies de propriedade intelectual possui características distintas.

No entanto, é possível adotar uma “concepção unitária” (BASSO, 2000: 51-55), que sublinha não as diferenças, mas os atributos compartilhados pelo conjunto de produtos da atividade criadora protegidos por direitos de propriedade. Uma metáfora ilustra bem essa abordagem: é a idéia de que a propriedade intelectual "deve ser entendida como um verdadeiro arquipélago, onde cada ilha, ou seja, cada uma das manifestações da criação intelectual guarda uma unidade e singularidade, mas todas elas possuem uma razão comum (caso contrário não seria um arquipélago) e todas elas estão sobre o mesmo oceano" (VIVANT apud BASSO, 2000: 53).

Encontramos na literatura estudos em que se optou por delimitar como área temática um subgrupo, ou ainda, uma espécie em particular dentro da propriedade intelectual ${ }^{6}$, mas também trabalhos que tratam do regime internacional da propriedade intelectual a partir dessa "concepção unitária"7 . Como veremos na Seção 3, a escolha por uma área temática mais abrangente, que abarca o conjunto de direitos de propriedade industrial, direitos autorais e direitos sui generis, considerando-os "ramos de uma mesma árvore" (BASSO, 2000: 49), encontra respaldo não apenas na unidade conceitual, mas também na tendência

indicações geográficas e direitos de autor. Há ainda aqueles que defendem que a natureza coletiva e ancestral desses direitos é incompatível com a lógica proprietária, e que, assim, esses conhecimentos seriam mais bem protegidos por sistemas sui generis estabelecidos fora do âmbito da propriedade intelectual. Em vários fóruns internacionais, como na Organização Mundial da Propriedade Intelectual (OMPI) e na Convenção sobre Diversidade Biológica (CDB), discute-se o estabelecimento de sistemas internacionais de proteção aos conhecimentos tradicionais, tanto dentro como fora do universo da propriedade intelectual.

${ }^{6}$ Ver CEPALUNI, 2006, que aborda o regime internacional de patentes.

${ }^{7}$ Ver, por exemplo, HELFER, 2004, YU, 2004 e ARAÚJO FILHO, 2007. 
histórica de convergência no tratamento dos direitos de propriedade intelectual. A Figura 1 ilustra a área temática da propriedade intelectual.

Figura 1: A área temática da propriedade intelectual

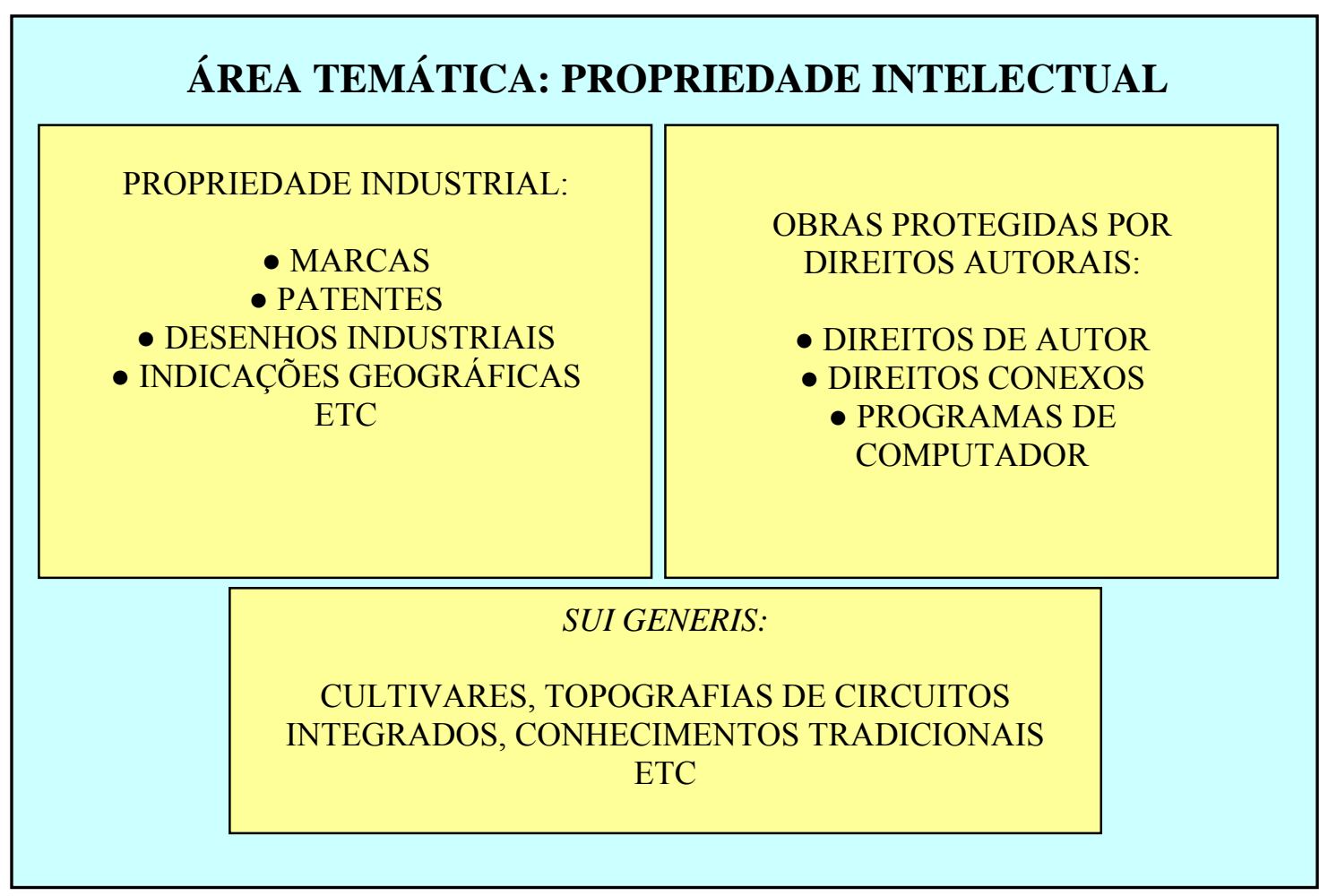

\subsection{Direitos de propriedade intelectual}

Hoje, praticamente todos os $\operatorname{Estados}^{8}$ garantem aos inventores e criadores dos produtos da atividade criativa, por meio da concessão ou do reconhecimento dos chamados

\footnotetext{
${ }^{8}$ Como veremos mais adiante, todos os países membros da OMC comprometeram-se a adotar "padrões mínimos" de proteção aos direitos de propriedade intelectual de que trata o Acordo sobre Aspectos de Propriedade Intelectual relacionados ao Comércio (Acordo TRIPS). As espécies cobertas por esse acordo são
} 
direitos de propriedade intelectual (DPIs), o direito exclusivo de gozar, fruir e dispor de suas criações pelo tempo que durar a proteção. Dessa forma, os DPIs correspondem, em linhas gerais, a um monopólio temporário ${ }^{9}$, garantido pelo Estado, que confere aos titulares desses direitos a faculdade de, enquanto durar o privilégio, excluir terceiros nãoautorizados de explorar o objeto protegido. A aquisição e o exercício do direito podem condicionar-se, ou não, a um registro no órgão nacional ou regional competente.

Uma característica importante dos DPIs é a territorialidade: via de regra, a proteção a esses direitos restringe-se aos limites de um país ou região. Ao mesmo tempo, o atributo da imaterialidade confere a esses ativos um caráter eminentemente internacional: as criações imateriais, "pela sua própria natureza, não se submetem a contenções e têm uma tendência irresistível a cruzar fronteiras" (BASSO, 2000: 23). Assim, torna-se imperioso proteger esses direitos não apenas no país ou região de origem da criação, mas também em todos aqueles países ou regiões em que o inventor ou criador tiver o interesse de exercer o seu monopólio temporário ${ }^{10}$.

Há diferentes justificativas para a concessão ou o reconhecimento desses direitos pelos Estados. Dolfsma (2006: 334), citando Hettinger, reconhece quatro diferentes rationales para os DPIs. As duas primeiras, que ressaltam o vínculo entre o inventor ou criador e a invenção ou criação, têm sido enfatizadas na Europa continental, bem como nos demais sistemas jurídicos sob a sua esfera de influência (DOLFSMA, 2006: 335). Na

\footnotetext{
${ }^{9}$ Alguns DPIs podem ter prazo de proteção indeterminado, como é o caso das indicações geográficas.

${ }^{10} \mathrm{Na}$ próxima seção veremos como o caráter internacional dos ativos intelectuais, aliado ao princípio da territorialidade, levou a que se passasse, ainda no final do século XIX, de regimes nacionais de proteção ao embrião de um regime internacional de propriedade intelectual.
} 
primeira perspectiva, denominada "sobremesa" (dessert), a concessão ou o reconhecimento de DPIs justificar-se-ia pelo entendimento de que quem produz um bem intelectual merece por isso alguma forma de recompensa. A segunda perspectiva tem fundamento pessoal/moral, a partir do qual o bem intelectual é entendido como a expressão da personalidade do inventor ou criador (DOLFSMA, 2006: 335) $)^{11}$.

Já a terceira e a quarta rationales, ambas de raiz utilitarista, têm predominado na Grã Bretanha e nos Estados Unidos (DOLFSMA, 2006: 334-335). Pela terceira perspectiva, a garantia de um período de tempo durante o qual a inovação possa ser explorada pelo inventor ou criador é vista como um incentivo ao desenvolvimento e à posterior difusão de novos conhecimentos. Finalmente, na quarta perspectiva os DPIs induziriam as firmas a investirem na produção de bens intelectuais, já que reduziriam os riscos envolvidos (DOLFSMA, 2006: 334). Diferentemente das duas primeiras rationales, que apresentam os DPIs como faculdades subjetivas do inventor ou criador, estas últimas têm caráter essencialmente econômico.

Embora prevaleça o entendimento dos DPIs como uma forma necessária de incentivo à inovação, ambas as visões, tanto a personalista (primeira e segunda rationales) quanto a utilitarista (terceira e quarta rationales), estão presentes no debate internacional sobre a matéria. Assim, referindo-se especificamente aos direitos de propriedade industrial, o manual "WIPO Intellectual Property Handbook", da Organização Mundial da Propriedade Intelectual - OMPI (2004: 164), sustenta que:

\footnotetext{
${ }^{11} \mathrm{O}$ reconhecimento do vinculo entre o inventor ou criador e a invenção ou criação a partir da concessão de um direito de propriedade tornou-se possível a partir da Revolução Francesa. Este ponto será retomado na próxima seção.
} 
"Countries have laws to protect industrial property for two main reasons, related to each other. One is to give statutory expression to the moral and economic rights of creators in their creations, and the other is to promote, as a deliberate government policy, creativity and the dissemination and application of its results, and to encourage fair trading: this contributes to economic and social development." (grifo da autora)

Em linha com a argumentação utilitarista, refletida na parte final do trecho acima, a proteção aos DPIs poderia ser justificada a partir da avaliação de que os bens intelectuais são bens públicos, categoria que agrega bens ao mesmo tempo não-excludentes - uma pessoa não pode ser impedida de utilizá-los - e não-rivais - a utilização do bem por alguém não impede que outros também o utilizem (MANKIW, 2005: 224). A consideração do conhecimento como "the quintessential public good", a exemplo de Drahos (2004: 321), ou mesmo como um bem público imperfeito ${ }^{12}$, como feito por Shaffer (2004: 462), acompanhando Stiglitz (apud SHAFFER, 2004: 462), desperta atenção para o fato de que a produção espontânea de bens intelectuais pelo mercado é desestimulada diante do risco de sua utilização por parte de caronas, o que leva à tendência de que esses bens sejam subofertados.

Nesse contexto, a proteção aos DPIs surge como estímulo ao desenvolvimento e oferecimento desses bens no mercado. Ao conceder ou reconhecer monopólios temporários de exploração de obras ou inventos inovadores, o Estado provisoriamente transforma esses bens públicos em bens privados, afastando, em tese, a hipótese de surgimento de caronas

\footnotetext{
${ }^{12}$ A caracterização do conhecimento como bem público imperfeito justificar-se-ia porque é possível que a não-excludência não esteja totalmente presente, como, por exemplo, nos casos em que o conhecimento é protegido por uma patente. Essa hipótese é também destacada por Mankiw, que aponta que o sistema de patentes torna excludentes os conhecimentos tecnológicos específicos (2005: 224).
} 
(SHAFFER, 2004: 461). Não apenas a produção desses bens seria incentivada, mas também, posteriormente, a sua difusão, tendo em vista que, após o decurso do prazo de proteção, o conhecimento em questão passaria a integrar o domínio público. Esse aspecto é ressaltado por Shaffer: "[K]nowledge and technological development can be viewed as public goods generated through the recognition and enforcement of private patent rights, provided that the invention is published in a public registry and the rights are limited in scope and time" (2004: 461) $)^{13}$.

A próxima seção demonstrará como o caráter essencialmente internacional dos bens intelectuais levou a que a proteção aos DPIs ultrapassasse a fronteira dos Estados, passando a ser internacional e, mais recentemente, global.

\footnotetext{
${ }^{13}$ Uma alternativa à proteção dos DPIs por parte do Estado, como forma de reduzir riscos e incentivar a produção desses bens públicos imateriais, seria a oferta de financiamento público. Shaffer ressalta que tanto uma como outra hipótese apresentam ineficiências e ineqüidades, que poderão ser reveladas por uma análise comparativa (2004: 462). Apesar da relevância dessas questões, não nos dedicaremos a elas neste trabalho.
} 


\section{A EVOLUÇÃO DA PROTEÇÃO À PROPRIEDADE INTELECTUAL}

Peter Drahos (1998) defende que, do surgimento das primeiras formas de proteção da propriedade intelectual até a atualidade, é possível identificar três períodos distintos: o período territorial, caracterizado pela ausência de proteção internacional; o período internacional, inaugurado com a celebração dos primeiros dois grandes tratados sobre a matéria, a Convenção de Paris e a Convenção de Berna, no final do século XIX; e o período global, marcado pelo advento do Acordo TRIPS, em 1994. Nesta seção faremos um breve histórico da proteção à propriedade intelectual, seguindo a periodização proposta por Drahos.

\subsection{Período territorial}

$\mathrm{Na}$ Europa medieval surgiram as primeiras marcas de fábricas, que pertenciam às corporações de ofício (BASSO, 2000: 66). Naquela mesma época já se concediam privilégios que se assemelhavam às atuais patentes. Em 1236 foi concedido em Bordeaux, na França, o privilégio mais antigo de que se tem notícia (BASSO, 2000: 66). Mais de dois séculos mais tarde, em 1474, Veneza editou a primeira lei de patentes, que já incorporava a idéia de que o inovador deveria ser recompensado pelo seu esforço, tendo em vista a importância estratégica da promoção da inovação e das práticas industriais competitivas (MAY apud YU, 2004: 5). Em 1623, foi editada a primeira lei inglesa de proteção às patentes, o Statute of Monopolies (BASSO, 2000: 67; DRAHOS, 1998: 3), que afastava todo monopólio que não pertencesse ao "verdadeiro e primeiro inventor" do "método de manufatura" (DRAHOS, 1998: 3). 
Surgiram igualmente na Idade Média os primeiros privilégios de publicação de obras, precursores dos diretos de autor. A mesma República de Veneza que "reivindica o título de ter sido o berço dos direitos sobre invenção industrial" (BASSO, 2000: 66) era considerada a "capital da imprensa"14 (PRAGER, apud YU, 2004: 6). Peter Yu alega que em 1493 foi concedido a Daniele Barbaro o primeiro privilégio de exclusividade na publicação de um livro, pelo prazo de dez anos (2004: 6), ao passo que Basso, citando Piolla-Caselli, defende que os privilégios mais antigos teriam sido concedidos em 1469, a Giovanni da Spira; em 1486, a Marco Antonio Sabellico; e em 1492, ao impressor Aldo (2000: 70). Em 1710, a Grã-Bretanha editou o Statute of Anne, que reconheceu aos autores o copyright e o direito de reprodução (BASSO, 2000: 70-71).

A partir da Revolução Francesa e das Declarações de Direitos Individuais, os direitos de propriedade intelectual deixaram de ser considerados como privilégios e passaram a ser entendidos como direitos do inventor ou criador (BASSO, 2000: 67-68). Nesse sentido, a “'Revolução Francesa marca o termo da evolução do direito de propriedade industrial' que 'deixa de se caracterizar como ato de arbítrio do soberano, muitas vezes destinado a favorecer algum favorito do momento, consolidando-se como direito subjetivo do inventor a obter o reconhecimento pelo seu esforço de criação"” (LEONARDOS apud BASSO, 2000: 68) ${ }^{15}$.

\footnotetext{
${ }^{14}$ A primeira patente teria sido concedida em Veneza em 1469, ainda antes do estatuto de 1474, justamente para uma printing press (YU, 2004: 6).

${ }^{15}$ A Revolução Francesa permite, portanto, o surgimento da visão personalista que, como visto na seção anterior, valoriza o mérito do inovador, ao apresentar os bens intelectuais como uma extensão da personalidade do inventor ou autor.
} 
A França revolucionária reconheceu o direito dos inventores em 1791, sendo que um ano antes, em 1790, os Estados Unidos haviam editado a sua primeira lei de patentes (BASSO, 2000: 68; DRAHOS, 1998: 3). No campo dos direitos de autor, em 1793 a lei francesa determinou que "todos os autores de escritos, compositores de músicas, arquitetos, escultores, pintores, desenhistas, gravadores de quadros e desenhos gozavam, durante toda a sua vida, do direito exclusivo de vender, distribuir suas obras no território da República, assim como ceder a propriedade, no todo ou em parte" (BASSO, 2000: 71). O Copyright Act norte-americano é de 1790 (DRAHOS, 1998: 6). A proteção das marcas de indústria, comércio e serviços surge em seguida, com as leis francesas de 1803 e 1857 (BASSO, 2000: 68), tendo legislações de proteção às marcas sido editadas em diversos países no decorrer do século XIX: na Inglaterra (1862 e 1875); na Alemanha (1874) e nos Estados Unidos (1870 e 1876) (DRAHOS, 1998: 4).

Apesar da influência mútua que os regimes nacionais de propriedade intelectual que proliferaram pela Europa e nos Estados Unidos exerciam uns sobre os outros ${ }^{16}$, não havia uniformidade entre eles. Além disso, em muitos países a proteção era restrita a nacionais e residentes $^{17}$ (YU, 2004: 7), ou mesmo inexistente (BASSO, 2000: 73).

Ao mesmo tempo, na segunda metade do século XIX a Revolução Industrial e as melhorias nos transportes e nas comunicações aceleraram tanto a produção quanto o comércio internacional de bens intelectuais (LADAS apud YU, 2004: 7). Nesse cenário, e

\footnotetext{
${ }^{16}$ A esse respeito, Drahos assinalou:"[i]t was a period of somewhat chaotic growth with much borrowing and cross-polination of intellectual property law between states" (DRAHOS, 1998: 4).

${ }^{17}$ Uma exceção foi um decreto promulgado na França em 1852 que conferia proteção às obras e autores estrangeiros, sem exigência de reciprocidade (DRAHOS, 1998: 5).
} 
na ausência de proteção internacional, acentuou-se o problema dos caronas (DRAHOS, 1998: 5): a cópia de criações que incorporavam as novas tecnologias e a pirataria ${ }^{18}$ de obras artísticas e literárias tornaram-se cada vez mais comuns.

Nessas circunstâncias, os países produtores de propriedade intelectual passaram a se interessar cada vez mais pela cooperação internacional nessa matéria (DRAHOS, 1998: 5). Era preciso coibir a cópia e a pirataria, o que exigiria "criar um direito internacional para a propriedade industrial que harmonizasse e unificasse regras de conflitos de leis e regras comuns de direito material" (BASSO, 2000: 73), necessidade igualmente presente na esfera dos direitos autorais.

\subsection{Período internacional}

A primeira tentativa de regulamentação da proteção à propriedade intelectual para além da esfera nacional foi a celebração de acordos bilaterais (DRAHOS, 1998: 5). Quanto maior a relação entre titulares e usuários de propriedade intelectual em um determinado país, maior tendia a ser a sua participação nos acordos bilaterais: "[t]hose states that were worried about the free-riding problem began to negotiate bilateral treaties with other states. Those states that saw themselves as recipients of a positive externality remained isolationist”' (DRAHOS, 1998: 5). No primeiro grupo de países estava a Grã-Bretanha; no

\footnotetext{
${ }^{18}$ Neste trabalho, o termo "pirataria" é utilizado no sentido estabelecido pelo Acordo TRIPS, de acordo com nota explicativa inserida no Artigo 51, segundo a qual "bens pirateados" devem ser entendidos como "quaisquer bens que constituam cópias efetuadas sem a permissão do titular do direito ou de pessoa por ele devidamente autorizada no país onde foi produzido e que são elaborados direta ou indiretamente a partir de um Artigo no qual a elaboração daquela cópia teria constituído uma violação de um direito autoral ou conexo na legislação do país de importação".
} 
segundo, os Estados Unidos, onde obras de escritores populares, como Dickens, eram freqüentemente republicadas sem autorização do titular ${ }^{19}$ (DRAHOS, 1998: 5).

Muitos desses acordos bilaterais continham cláusulas de reciprocidade: os direitos dos nacionais ou domiciliados no país A só seriam protegidos no país B se os nacionais ou domiciliados do país B também tivessem seus direitos garantidos no país A. Ao lado do princípio da reciprocidade figurava o principio do tratamento nacional: tanto um como outro país assumiam que, no que diz respeito à proteção da propriedade intelectual, não discriminaria entre nacionais e estrangeiros (DRAHOS, 1998: 6).

A despeito do grande número de acordos bilaterais em matéria de propriedade intelectual celebrados no período (em 1883 havia 69 tratados em vigor, a maior parte relativa a marcas - DRAHOS, 1998: 6), a proteção por eles conferida nunca foi satisfatória (LADAS apud DRAHOS, 1998: 6). Isso porque a rede de tratados que se constituiu não resultou em maior uniformidade ou certeza quanto à proteção aos direitos intelectuais fora dos países de origem. Ao contrário: na prática era difícil saber qual o nível de proteção conferida a uma obra originada em outro país. Freqüentemente esses acordos estavam inseridos em acordos comerciais mais amplos, portanto sujeitos a eventual revogação ou renegociação. Adicionalmente, muitos dos acordos bilaterais continham a chamada “cláusula da nação mais favorecida”, que estendia a um país condições mais favoráveis que outro país tivesse concedido, em outro tratado, a uma terceira parte (YU, 2004: 8), aumentando ainda mais a complexidade do sistema.

\footnotetext{
${ }^{19} \mathrm{O}$ Copyright Act norte-americano, a que já se fez menção, conferia proteção apenas a nacionais e residentes.
} 
Diante dessa realidade, não chegou a surpreender o fato de os expositores convidados a participar da Exposição Internacional de Viena, realizada em 1873, terem hesitado em apresentar ali as suas invenções (YU, 2004: 15). As causas dessa hesitação, que foi especialmente notada entre inventores norte-americanos, são explicitadas na edição de 23 de dezembro da revista Scientific American, em que se argumenta, a esse respeito, que "[t] he value of Austrian patents issued to Americans and other foreigners can be easily escheated to the benefit of the Austrian public" (LADAS apud YU, 2004: 15). Diante disso, o governo austríaco decidiu realizar naquele mesmo ano de 1873 um Congresso de especialistas que, entre outros resultados, destacou que "the necessity of reform is evident, and it is of pressing moment that Governments should endeavor to bring about an international understanding upon patent protection as soon as possible" (LADAS apud YU, 2004: 16).

Em 1878, por ocasião da Exposição Internacional de Paris, foi organizado o Congresso Internacional sobre Propriedade Industrial, mas os cerca de 500 participantes não lograram obter consenso quanto à constituição de uma união multipartite ou quanto a como e quais regras universais deveriam ser adotadas pela comunidade internacional (YU, 2004: 16).

As discussões prosseguiram e em 1880 foi realizada na mesma cidade de Paris outra conferência internacional, que teve continuidade em 1883. Nessa oportunidade, foi finalmente adotado o primeiro acordo multilateral sobre propriedade intelectual: a Convenção de Paris para a Proteção da Propriedade Industrial, também conhecida como Convenção da União de Paris (CUP) ou, simplesmente, Convenção de Paris. 
A CUP foi inicialmente assinada por onze países ${ }^{20}$, a que se juntaram outros quatro $^{21}$ um ano mais tarde (YU, 2004: 18). Vinte e cinco anos depois, a maior parte dos países com tradição em comércio internacional faziam parte da CUP (DRAHOS, 1998: 7). Hoje são 172 as partes contratantes ${ }^{22}$.

A Convenção de Paris instituiu a "União para a Proteção da Propriedade Industrial” e o "Bureau da União de Paris", a que coube a função de Secretariado Executivo da União (BASSO, 2000: 74). Em termos substantivos, a CUP consagrou dois princípios: o princípio do tratamento nacional e o princípio da prioridade unionista. Já fizemos referência ao princípio do tratamento nacional, que corresponde à obrigatoriedade de um país conceder aos estrangeiros tratamento não menos favorável (ou seja, tão favorável quanto, ou melhor) do que o dado aos nacionais.

O principio da prioridade unionista, por sua vez, permite que aquele que solicita uma patente em um país estrangeiro mantenha a data mais antiga da solicitação da mesma patente em seu país de origem, evitando que seus pedidos sofram oposição em razão de publicação, pedido ou uso anterior (YU, 2004: 18).

\footnotetext{
${ }^{20}$ Bélgica, Brasil, El Salvador, Espanha, França, Guatemala, Itália, Países Baixos, Portugal, Sérvia e Suíça. É curioso notar que, à época, nem os Países Baixos nem a Suíça ofereciam proteção patentária aos seus nacionais. Prevaleceu o principio do tratamento nacional em detrimento do princípio da reciprocidade não se aplicou ao caso e esses países ficaram desobrigados de oferecer proteção patentária a estrangeiros (YU, 2004: 18).

${ }^{21}$ Equador, Grã-Bretanha e Irlanda, e Tunísia. Equador retirou-se da Convenção em 1885 (YU, 2004: 18).

${ }^{22}$ Dado disponível na página www.wipo.int/treaties/en/showresults.jsp?lang=en\&treaty id=2, acessada em 10 de março de 2008.
} 
A Convenção de Paris não chegou a unificar as leis de patentes e marcas dos países signatários (YU, 2004: 18). No entanto, a Convenção fixou, pela primeira vez, "padrões mínimos" de proteção aos direitos de propriedade industrial, "abaixo do[s] qual[is] nenhum país unionista pode ficar" (BASSO, 2000: 76).

Já foi dito que Convenção de Paris

"is not merely a compact between the individual countries parties to it with reciprocal rights and obligations; it is rather an instrument seeking to regulate interests, claims, and demands pressing upon the national and international level. It has adopted, by its stipulations, a legal ordering which seeks to satisfy the greatest number of the scheme of interests involved with the least sacrifice to any" (LADAS apud YU, 2004: 19 - grifo da autora)

As discussões para o estabelecimento de um tratado sobre a proteção aos direitos autorais seguiram em paralelo às que culminaram na adoção da CUP. Assim, em 1878 foi instituída a "Associação Literária e Artística Internacional", que tinha por objetivo o reconhecimento melhor e mais eficaz dos direitos dos autores sobre suas obras, em escala internacional (BASSO, 2000: 89). Em 1882 a Associação, que era presidida pelo novelista francês Victor Hugo, reuniu-se novamente em Roma e um ano mais tarde, em Berna. Uma série de conferências intergovernamentais foi realizada nessa cidade suíça até 1886, ano em que foi concluída a versão final da Convenção de Berna para a Proteção de Obras Literárias e Artísticas, ou simplesmente Convenção de Berna (YU, 2004: 9). 
Inicialmente, a Convenção de Berna foi assinada por dez países ${ }^{23}$. Os Estados Unidos e o Japão, que participavam da conferência final como observadores, não aderiram ao tratado de imediato: o Japão aderiu à Convenção em 1899 e os Estados Unidos, apenas em 1889. Hoje, a Convenção de Berna conta com 163 partes contratantes ${ }^{24}$.

Assim como a Convenção de Paris, a Convenção de Berna também instituiu uma União: a "União para a Proteção dos Direitos de Autor em suas Obras Artísticas e Literárias"; e um Bureau para servi-la como Secretariado Executivo: o "Bureau da União de Berna", a que coube a função de Secretariado Executivo da União (BASSO, 2000: 74).

O princípio do tratamento nacional, consagrado pela Convenção de Paris, também integrou a Convenção de Berna (YU, 2004: 10).

Em 1892, os Bureaus de Paris e de Berna se uniram e constituíram o "Bureaux Internationaux Réunis Pour la Protection de la Propriété Intelectuelle" (BIRPI). Com a criação da Organização Mundial da Propriedade Intelectual (OMPI), em 1967, o BIRPI passou a integrar essa nova organização, recebendo então o nome de "Secretaria Internacional” (BASSO, 2000: 91). Em 1974 a OMPI se tornou uma agência especializada das Nações Unidas (DRAHOS, 1998: 8).

Apesar de estabelecerem padrões mínimos de proteção, nem a Convenção de Paris, nem a Convenção de Berna apresenta dispositivos específicos sobre a observância dessas

\footnotetext{
${ }^{23}$ Alemanha, Bélgica, Espanha, França, Grã-Bretanha, Haiti, Itália, Libéria, Suíça e Tunísia.

${ }^{24}$ Dado disponível na página www.wipo.int/treaties/en/showresults.jsp?lang=en\&treaty id=15, acessada em 10 de março de 2008.
} 
regras. Quanto à solução de controvérsias, para os conflitos que não fossem solucionados pela via da negociação havia apenas, em ambas as Convenções, a previsão da possibilidade de recurso à Corte Internacional de Justiça. No entanto, a maior parte dos países apresentou reservas quanto a esses dispositivos ao aderir às Convenções (DRAHOS, 1998: 9). Como resultado, esse mecanismo nunca foi utilizado (GOLDSTEIN apud YU, 2004: 20). Com base nisso, $\mathrm{Yu}$ conclui que "the Berne and the Paris Conventions are virtually unenforceable except by coercion or diplomacy, and none of them provides any effective dispute resolution mechanism" (2004: 20).

Desde a sua entrada em vigor, tanto a Convenção de Paris quanto a Convenção de Berna passaram por diversas revisões e emendas, sete no primeiro caso e oito no segundo (BASSO, 2000: 74 e 90). Essas revisões contribuíram para uma uniformização "gradual e incremental" na regulamentação internacional da propriedade industrial e dos direitos de autor (CORREA e YUSUF, 1998: xvii).

Quanto à Convenção de Berna, a revisão mais significativa ocorreu na Conferência de Estocolmo, realizada em 1967 (YU, 2004: 11). Entre outras alterações, a "Ata de Estocolmo" estabeleceu um Protocolo sobre Países em Desenvolvimento, que tinha por finalidade permitir que países menos desenvolvidos estabelecessem limitações amplas aos direitos de tradução e reprodução (YU, 2004: 11). Apesar de, no entender de Yu, tal Protocolo responder a uma demanda legítima desses países por maior acesso à informação e ao conhecimento, ele não foi bem recebido pelos países desenvolvidos. Como resultado, a Ata de 1967 nunca foi ratificada (YU, 2004: 12). O conteúdo da Ata de Estocolmo acabou 
sendo incorporado, em grande medida, na Ata de Paris, adotada na Convenção realizada na capital francesa em 1971 (YU, 2004: 12).

Ainda na fase internacional, além da Convenção de Paris e da Convenção de Berna, foram instituídos outros tratados multilaterais sobre propriedade intelectual (propriedade industrial, direitos autorais e sui generis), a quase totalidade deles no âmbito da OMPI ou do antigo BIRPI $^{25}$, como destacado na tabela a seguir.

Tabela1: Acordos multilaterais sobre propriedade intelectual celebrados no período internacional, entre 1886 e 1995

\begin{tabular}{|c|c|}
\hline $\begin{array}{l}\text { ÁREA DENTRO DA } \\
\text { PROPRIEDADE } \\
\text { INTELECTUAL }\end{array}$ & ACORDOS \\
\hline Propriedade industrial & $\begin{array}{l}\text { - Acordo e Protocolo de Madri sobre o Registro Internacional } \\
\text { de Marcas (respectivamente, } 1891 \text { e 1989); } \\
\text { - Acordo de Madri sobre indicações de procedência (1891); } \\
\text { - Acordo de Haia relativo ao Depósito Internacional de } \\
\text { Modelos e Desenhos Industriais (1923); } \\
\text { - Acordo de Nice relativo à Classificação Internacional de } \\
\text { Produtos e Serviços para o Registro de Marcas (1957); } \\
\text { - Acordo de Lisboa relativo à Proteção das Denominações de } \\
\text { Origem e seu Registro Internacional (1958); } \\
\text { - Acordo de Locarno que Estabelece uma Classificação } \\
\text { Internacional para os Desenhos e Modelos Industriais (1968); } \\
\text { - Tratado de Cooperação em Matéria de Patentes (PCT, 1970); } \\
\text { - Acordo de Estrasburgo relativo à Classificação Internacional } \\
\text { de Patentes (IPC, 1971); } \\
\text { - Acordo de Viena para a Instituição de uma Classificação } \\
\text { Internacional dos Elementos Figurativos das Marcas (1973); } \\
\text { - Tratado de Budapeste sobre o Reconhecimento Internacional } \\
\text { do Depósito de Microorganismos para Fins de Procedimentos } \\
\text { em Matéria de Patentes (1981); }\end{array}$ \\
\hline
\end{tabular}

\footnotetext{
${ }^{25}$ A única exceção é a Convenção Internacional para a Proteção de Novas Variedades Vegetais, mantido pela
} União Internacional para a Proteção de Obtenções Vegetais (UPOV). 


\begin{tabular}{|c|c|}
\hline $\begin{array}{l}\text { Direitos de autor e } \\
\text { conexos }\end{array}$ & $\begin{array}{l}\text { - Tratado de Nairobi relativo à Proteção do Símbolo Olímpico } \\
\text { (1981); } \\
\text { - Tratado sobre Direitos de Marcas (TLT, 1994) } \\
\text { - Convenção de Genebra para a Proteção dos Produtores de } \\
\text { Fonogramas contra a Reprodução não Autorizada de seus } \\
\text { Fonogramas (1971) } \\
\text { - Convenção de Bruxelas sobre a Distribuição de Sinais } \\
\text { Portadores de Programas Transmitidos por Satélite (1974) }\end{array}$ \\
\hline Sui generis & $\begin{array}{l}\text { - Tratado de Washington sobre Propriedade Intelectual em } \\
\text { Matéria de Circuitos Integrados (1989) } \\
\text { - Convenção Internacional para a Proteção de Novas } \\
\text { Variedades Vegetais, Atas 1972, } 1978 \text { e } 1991 \text { - mantida pela } \\
\text { União Internacional para a Proteção de Obtenções Vegetais } \\
\text { (UPOV) }\end{array}$ \\
\hline
\end{tabular}

\subsection{Período global}

A partir do final da Segunda Guerra, cresceu a importância relativa da propriedade intelectual para os países desenvolvidos, notadamente para os Estados Unidos, em função de as indústrias de informação e entretenimento terem passado a ser responsáveis por uma parte substancial do Produto Interno Bruto de muitos desses países (YU, 2004: 21). "For the U.S. film and pharmaceutical industries in particular," ilustra Drahos, "intellectual property (copyright in the former, patents for the latter) represented the backbone of their industries" (1998: 9).

Interessados em explorar ao máximo a sua recém adquirida vantagem comparativa (OKEDIJI, 2004: 134), esses países reagiram negativamente à crescente demanda por reformas na Convenção de Paris, por parte dos países em desenvolvimento e de menor desenvolvimento relativo, a partir de meados dos anos 1970. Tendo em vista a sua pequena 
participação como ofertantes no mercado de bens imateriais, estes países demandavam a redução dos "padrões mínimos" previstos na CUP, no que dizia respeito à aplicação desses padrões ao mundo em desenvolvimento (YU, 2004: 21).

Como reflexo do processo de descolonização na segunda metade do século XX, mais e mais países em desenvolvimento e de menor desenvolvimento relativo haviam aderido às Convenções de Paris e de Berna (DRAHOS, 1998: 8). A vantagem numérica desse grupo frente ao grupo dos países desenvolvidos, aliada à regra "um país, um voto", fazia parecer que o ambiente da OMPI poderia ser favorável ao atendimento das suas demandas.

No entanto, o processo de revisão da Convenção de Paris acabou chegando a um impasse na Conferência Diplomática de Nairobi, em 1981, diante da forte objeção dos Estados Unidos a novas regras sobre licenciamento compulsório de patentes, demandadas por países de menor desenvolvimento (YU, 2004: 21). A rejeição ao Protocolo sobre Países em Desenvolvimento na Conferência de Estocolmo (1967) sobre a Convenção de Berna, de que tratamos na seção anterior, pode ser entendida como um prenúncio de que os países desenvolvidos não estavam dispostos a ceder.

Com efeito, era crescente a preocupação dos países desenvolvidos com o desrespeito aos seus direitos de propriedade industrial e com a pirataria. Isso tinha levado a que, ao final da Rodada Tóquio da Organização Mundial do Comércio (OMC), esses países tivessem tentado, sem sucesso, incluir no Acordo Geral sobre Tarifas e Comércio (GATT) 
um "código anti-contrafação", que previa medidas de fronteira para a interceptação e destruição de bens intelectuais que desrespeitassem DPIs (YU, 2004: 21).

Finalmente, no entanto, no lançamento da Rodada Uruguai os países desenvolvidos lograram incluir na Declaração Ministerial de Punta del Este a disciplina da propriedade intelectual. Mais especificamente, foram inseridos no mandato negociador os "aspectos dos direitos de propriedade intelectual relacionados ao comércio, incluindo bens contrafeitos" (YU, 2004: 21). Essa inclusão havia sido uma proposta essencialmente dos Estados Unidos, mas que contou com o apoio da Europa ${ }^{26}$, Canadá e Japão (DRAHOS, 1998: 10).

Como esclarecido por Drahos (1998: 9), levar as discussões de propriedade intelectual para o âmbito do GATT/OMC trazia, do ponto de vista dos países desenvolvidos, duas vantagens principais. Em primeiro lugar, a inclusão de padrões de proteção à propriedade intelectual em um acordo multilateral de comércio faria com que esses padrões passassem a ter uma cobertura mais ou menos global, já que se tornariam vinculantes a todos os futuros membros da OMC.

Em segundo lugar, passaria a ser possível utilizar, em controvérsias que envolvessem propriedade intelectual, os mecanismos de observância que fossem desenvolvidos para resolver as disputas comerciais, inclusive com a possibilidade de retaliação cruzada. Esse talvez tenha sido o efeito mais significativo da inclusão do tema no GATT/OMC, especialmente tendo em vista o insucesso dos tratados administrados pela OMPI neste aspecto, como visto anteriormente.

\footnotetext{
${ }^{26} \mathrm{O}$ apoio europeu condicionou-se à inclusão do tema das indicações geográficas, como se verá em seguida.
} 
Adicionalmente, no GATT/OMC os países desenvolvidos teriam maior poder de barganha, já que poderiam negociar a proteção à propriedade intelectual em troca da promessa de abertura (ou ameaça de fechamento) dos seus mercados aos produtos dos países em desenvolvimento, em sua maioria agrícolas e têxteis (HELFER, 2004: 21).

Para os países em desenvolvimento, além da promessa de maior acesso aos mercados dos países desenvolvidos, havia também a expectativa de que a inclusão da temática da propriedade intelectual no âmbito do GATT/OMC arrefecesse a agressiva política unilateral que os Estados Unidos vinham adotando nesta matéria desde os anos $1980^{27}$ (HELFER, 2004: 21).

Essa política, que passou a ser utilizada deliberadamente como forma de isolar países em desenvolvimento que se opunham à inclusão de temas substantivos de propriedade intelectual no GATT/OMC (como Argentina, Brasil, Coréia, Índia, México e Tailândia) e persuadi-los a alterar as suas posições, foi bem sucedida: "[t]hese sanctions ultimately divided the less developed countries and induced them to agree to the United States' position" (YU, 2004: 24).

O fundamento legal para a política de sanções unilaterais era a Lei de Comércio e Tarifas de 1974, cuja "Seção 301” “conferiu poder discricionário ao Executivo norte-

\footnotetext{
${ }^{27}$ Van Bael e Bellis ressaltam que, em menor medida, também a Europa fazia uso de medidas unilaterais dessa natureza: o "New Commercial Policy Instrument", de 1984, também autorizava sanções comerciais contra países envolvidos em atos de "comércio ilícito", incluindo a proteção inadequada à propriedade intelectual de firmas européias (apud SHADLEN, 2005: 33).
} 
americano para fazer uso de (...) medidas coercitivas contra políticas e práticas comerciais de Governos estrangeiros consideradas prejudiciais aos interesses norte-americanos." (ARSLANIAN, 1994: 7). Em 1988, essa legislação foi aperfeiçoada pela Lei Abrangente de Comércio e Competitividade, que criou as chamadas "Super 301", com listas de países e práticas prioritárias em matéria de barreiras comerciais, e "Special 301", direcionada especificamente àqueles países que deixassem de atender aos requisitos estabelecidos pelos Estados Unidos para a proteção aos direitos de propriedade intelectual (ARSLANIAN, 1994: 7$)^{28}$

Alvos preferenciais das políticas unilaterais norte-americanas, e a despeito de a Declaração de Punta del Este mencionar a elaboração de novas regras e disciplinas, além de reconhecer a necessidade de promover proteção efetiva e adequada aos DPIs e prever o desenvolvimento de um framework multilateral de princípios, regras e disciplinas relativas ao comércio de bens contrafeitos, países como Brasil e Índia inicialmente resistiram à inclusão de temas substantivos de propriedade intelectual no GATT/OMC (WATAL apud YU, 2004: 23). O argumento central desses países era que a propriedade intelectual era matéria de competência exclusiva da OMPI (YU, 2004: 22), embora na Declaração Ministerial houvesse apenas sido ressalvado o trabalho complementar levado a cabo na OMPI e em outros fóruns (WATAL apud YU, 2004: 23).

\footnotetext{
${ }^{28} \mathrm{Na}$ prática, os Estados Unidos seguiram aplicando tais medidas, como podia-se antecipar ainda em 1994, com a reedição por decreto presidencial da "Special 301", conforme sublinhado à época por Arslanian (1994: 155).
} 
No início, também os países europeus hesitaram em aceitar a inclusão de padrões mínimos de proteção aos DPIs nas negociações da Rodada Uruguai, ao argumento de que apenas o comércio de bens contrafeitos guardava relação com o mandato do GATT/OMC (YU, 2004: 22) e que o uso abusivo dos DPIs poderia se tornar uma barreira ao comércio. No entanto, após a aceitação, por parte dos Estados Unidos, da demanda européia de inclusão nas negociações da proteção às indicações geográficas, os europeus não apenas aceitaram a inclusão de temas substantivos como apresentaram uma proposta ambiciosa, já em linguagem de tratado, que cobria a aquisição, observância e princípios básicos para a proteção da propriedade intelectual (GERVAIS apud YU, 2004: 24)

Em seguida, em 11 de maio de 1990 os Estados Unidos apresentaram uma proposta bastante semelhante à proposta européia, já em linguagem de tratado, cuja estrutura assemelha-se bastante à do texto final do Acordo TRIPS (GERVAIS apud YU, 2004: 24).

Apesar da resistência inicial, em 14 de maio de 1990 também o chamado "Grupo dos 14",29, formado por países em desenvolvimento, apresentou uma proposta, que priorizava o tratamento dado ao comércio de bens contrafeitos, em detrimento das medidas que fixavam padrões mínimos de proteção aos DPIs. Além disso, era dado destaque aos objetivos de políticas públicas subjacentes a essa proteção, isto é, o desenvolvimento econômico, social e tecnológico, bem como à necessidade de respeitar e salvaguardar as tradições jurídicas nacionais, tendo em vista as diferentes necessidades e níveis de desenvolvimento dos países que participavam das negociações da Rodada Uruguai

\footnotetext{
${ }^{29} \mathrm{O}$ "Grupo dos 14" era formado por Argentina, Brasil, Chile, China, Colômbia, Cuba, Egito, Índia, Nigéria, Paquistão, Peru, Tanzânia, Uruguai e Zimbábue.
} 
(YUSUF, 1998: 9-10). Esses princípios acabaram sendo incorporados ao texto final do Acordo.

Em resumo, Maristela Basso (2000: 164-165) destaca três concepções distintas que estavam presentes nos debates que culminaram na adoção do Acordo TRIPS. A primeira delas, defendida pelos Estados Unidos, sublinhava o papel instrumental da propriedade intelectual para favorecer a inovação, as invenções e a transferência de tecnologia em todos os países, independentemente do seu nível de desenvolvimento econômico. A segunda concepção, sustentada pelos países em desenvolvimento, enfatizava a necessidade de assegurar o acesso desses países às novas tecnologias, tendo em vista as suas necessidades específicas de desenvolvimento econômico e social. A terceira concepção, defendida pelos europeus e outros países desenvolvidos com posição intermediária, apontava para a necessidade de garantir a proteção efetiva aos DPIs e, ao mesmo tempo, evitar abusos no exercício desses direitos que pudessem restringir o comércio legítimo.

Tendo em conta esses diferentes posicionamentos, e para superar o impasse a que haviam chegado países desenvolvidos e em desenvolvimento no início dos anos 1990, o presidente do Grupo de Negociações de TRIPS, Lars Anell, preparou uma proposta de acordo com o que entendia ser aceitável para todas as partes. Essa proposta, que se tornou conhecida como Dunkel Draft, resultou, após pequenas alterações, no texto final do Acordo TRIPS, aprovado na Reunião Ministerial de Marrakesh, realizada em abril de 1994 (GERVAIS e WATAL apud YU, 2004: 25).

A respeito do texto final do Acordo TRIPS, Maristela Basso comenta: 


\begin{abstract}
"Certamente, o texto ficou aquém das expectativas dos países desenvolvidos, que buscavam no GATT patamares superiores de proteção dos direitos de propriedade intelectual. Por outro lado, os países em desenvolvimento, que buscavam assegurar a difusão de tecnologia, destacando as assimetrias Norte-Sul, comprometeram-se a implementar medidas eficazes e apropriadas para a aplicação de normas de proteção desses direitos relacionadas ao comércio, na perspectiva da cooperação internacional." (BASSO, 2000: 167)
\end{abstract}

Os diferentes aspectos cobertos pelo Acordo TRIPS distribuem-se pelas sete partes em que o tratado se divide. A primeira parte trata das disposições gerais e princípios básicos. Nesta seção estão incluídos, entre outros aspectos, as menções à nação mais favorecida e ao tratamento nacional, além dos princípios "development friendly" originados da proposta do "Grupo dos 14", mencionados acima.

A segunda parte aborda as espécies de DPIs (direitos de autor e direitos conexos, marcas, indicações geográficas, desenhos industriais, patentes, topografia de circuitos integrados, proteção de informação confidencial e controle de práticas de concorrência desleal em contratos de licenças), elevando os padrões mínimos de proteção relativos à existência, abrangência e eficácia desses direitos. Aqui foram criadas, entre outras, novas obrigações para os países nas áreas de patentes de produtos alimentícios, farmacêuticos, químicos e microorganismos (WATAL apud YU, 2004: 26).

A terceira parte cuida da aplicação das normas de proteção aos DPIs, estabelecendo, pela primeira vez, padrões internacionais para a observância de DPIs, incluindo procedimentos civis, administrativos e criminais, medidas cautelares e medidas de 
fronteira. A quarta parte trata da obtenção e manutenção dos DPIs, bem como de procedimentos inter-partes, como oposição, cancelamento e revogação.

A quinta parte abrange a prevenção e a solução de controvérsias, estabelecendo que qualquer controvérsia que surja em função da aplicação do Acordo TRIPS deverá ser solucionada por meio do mecanismo de solução de controvérsias da OMC.

A sexta parte apresenta os arranjos transitórios, determinando diferentes prazos de transição para a entrada em vigor das obrigações do Acordo TRIPS para países desenvolvidos, países em transição para economia de mercado, países em desenvolvimento e países de menor desenvolvimento relativo ${ }^{30}$.

Por fim, a sétima parte apresenta os arranjos institucionais, incluindo as atribuições do Conselho dos Aspectos de Propriedade Intelectual relacionados ao Comércio (ou simplesmente Conselho de TRIPS), e as disposições finais, que ressaltam, entre outros aspectos, que o Acordo não admite reservas, salvo com o consentimento de todos os demais Membros $^{31}$.

O Acordo TRIPS representou um salto qualitativo em relação aos tratados anteriormente negociados em matéria de propriedade intelectual. Como destacado por

\footnotetext{
${ }^{30}$ Prazos de transição: a) países desenvolvidos: 1 ano (1/1996); b) países em desenvolvimento e países em transição para economia de mercado: 1 ano +4 anos $=5$ anos $(1 / 2000)$; c) países de menor desenvolvimento relativo: 10 anos (1/2005) (prazo recentemente prorrogado); d) prazo para proteção de setores tecnológicos anteriormente não protegidos, em países em desenvolvimento: 1 ano +4 anos +5 anos $=10$ anos $(1 / 2005)$

${ }^{31} \mathrm{O}$ texto do acordo pode ser acessado em. A versão em português, internalizada pelo Decreto , pode ser acessada em .
} 
Carlos Correa e Abdulqawi Yusuf, trata-se do "most far-reaching and comprehensive legal regime ever concluded at the multilateral level in the arena of intellectual property rights (IPRs)" (1998: xvii). No mesmo sentido, J. H. Reichman acrescenta: "[t]he TRIPS Agreement is the most ambitious international intellectual property convention ever attempted" (apud YU, 2004: 25).

Na Reunião Ministerial de Marrakesh, mais de 100 países assinaram a "Ata Final que Incorpora os Resultados da Rodada Uruguai de Negociações Comerciais Multilaterais do GATT" (Drahos, 1998: 10). Em julho de 2007, os membros da OMC totalizavam $151^{32}$. Os dispositivos do Acordo TRIPS tornaram-se vinculantes para todos esses países.

Após a conclusão do Acordo TRIPS, as negociações internacionais em matéria de propriedade intelectual prosseguiram, tendo em vista não apenas a implementação desse Acordo, mas também, e de forma bastante intensa, o estabelecimento de novos compromissos nesse tema. Esse movimento tem sido percebido tanto na esfera multilateral (OMC e OMPI), quanto em negociações regionais e bilaterais.

No âmbito da OMC, a Declaração Ministerial de Doha, de novembro de 2001, incluiu três temas centrais de propriedade intelectual em seu mandato negociador: a relação entre o Acordo TRIPS e a saúde pública; a relação entre o Acordo TRIPS e a Convenção sobre Diversidade Biológica $(\mathrm{CDB})$; e o aprofundamento da proteção às indicações geográficas.

\footnotetext{
${ }^{32}$ Dado disponível na página www.wto.org/english/thewto_e/whatis_e/tif_e/org6 e.htm, acessada em 10 de março de 2008.
} 
A discussão do primeiro tema resultou na adoção, ainda em 2001, da "Declaração sobre o Acordo TRIPS e Saúde Pública", que reafirma que o Acordo TRIPS deve ser interpretado e implementado de forma a apoiar a saúde pública, e culminou na aprovação da primeira emenda ao Acordo TRIPS, que tem por objetivo garantir que, em circunstâncias especificas, também países com pouca ou nenhuma capacidade de fabricação local possam fazer uso do instrumento da licença compulsória.

O debate sobre o segundo tema tem girado em torno de proposta de emenda, apresentada pelo Brasil, Índia e outros países ricos em biodiversidade, que tem por objetivo tornar o Acordo TRIPS compatível com a CDB. Em especial, a proposta pretende tornar obrigatório que o requerente de patente que faça uso de recurso genético ou de conhecimento tradicional revele a origem de tal recurso ou conhecimento ("disclosure"), além de comprovar a obtenção do consentimento prévio informado e a repartição de benefícios com o provedor do recurso ou conhecimento utilizado.

Quanto ao aprofundamento da proteção às indicações geográficas, trata-se de demanda da União Européia, que pretende, de um lado, avançar na negociação de um "sistema multilateral de notificação e registro" de indicações geográficas de vinhos e destilados e, de outro, estender, a outros produtos, a proteção adicional prevista no Acordo TRIPS para vinhos e destilados.

Na OMPI, foram negociados e aprovados o Tratado sobre Direitos de Autor (WCT, 1996) e o Tratado sobre Interpretação ou Execução de Fonogramas (WPPT, 1996), que têm 
como foco a proteção dos direitos autorais em ambiente digital. Avançaram também negociações substantivas em matéria de patentes (Tratado Substantivo em Matéria de Patentes - SPLT, na sigla em inglês) e direitos conexos (Tratado de Radiodifusão), embora, nestes casos, o processo não tenha resultado, ainda, em textos acordados.

É importante ressaltar que a inclusão do tema de propriedade intelectual na OMC, a partir da Rodada Uruguai, não significou perda de autoridade da OMPI, mas apenas que, dali em diante, cada uma das duas organizações passaria a cuidar de áreas específicas dentro do tema. Enquanto à OMC caberia enfatizar a implementação, a observância e a resolução de controvérsias, a OMPI focaria a geração de novas formas de proteção à propriedade intelectual, a administração dos tratados existentes e a assistência técnica aos países em desenvolvimento (HELFER, 2004: 25).

Os avanços recentes mais significativos em matéria de propriedade intelectual têm ocorrido, não na OMC ou na OMPI, mas nas negociações de acordos comerciais bilaterais e regionais. David Vivas-Eugui destaca três razões para esse fenômeno: o maior interesse dos países desenvolvidos em proteger suas tecnologias e criações da apropriação por caronas; a necessidade de consolidar e expandir o acesso de produtos e serviços com alto valor tecnológico em terceiros mercados; e a crença de que as negociações bilaterais ou regionais envolvendo propriedade intelectual só fazem sentido se levarem a níveis de proteção mais altos do que os consolidados no nível multilateral (2003: 5).

Bryan Mercurio (2006: 215) esclarece este último ponto: 
"Having unsuccessfully attempted to strengthen IPRs in TRIPS in the years following its implementation, and following the spectacular failure of the Seattle Ministerial in 1999, these nations shifted the focus of their efforts from the multilateral forum to bilateral and regional Free Trade Agreements (FTAs). Thus, while many developing countries were struggling to implement their obligations under TRIPS, developed countries were already raising the level of IPRs through FTAs.”

Em linhas gerais, tais acordos incorporam cláusulas TRIPS-plus (proteção maior do que o mínimo exigido na categoria pelo Acordo TRIPS) e TRIPS-extra (proteção para categoria não abrangida por TRIPS), além de afastar flexibilidades garantidas no Acordo TRIPS. Via de regra, a contrapartida à aceitação desses dispositivos pelos países em desenvolvimento é maior acesso aos mercados dos países desenvolvidos.

É importante notar que os novos níveis de proteção estabelecidos nesses acordos não necessariamente ficarão restritos à esfera bilateral ou regional. Ao contrário, a tendência é que eles venham a ser incorporados ao framework internacional de proteção à propriedade internacional.

Isso poderá ocorrer de três formas. Em primeiro lugar, a aplicação do princípio da nação mais favorecida, que, como vimos, vincula todos os países membros da OMC, bem como todas as partes das Convenções de Paris e de Berna, poderá levar a que qualquer vantagem, favorecimento, privilégio ou imunidade concedido nesses acordos sejam obrigatoriamente estendidos, sem qualquer contrapartida, aos demais países que integram o sistema multilateral de comércio. 
Em segundo lugar, os padrões elevados de proteção consagrados pelos acordos bilaterais e regionais poderão passar a ser considerados como direito internacional costumeiro, o que tornaria difícil afastar a sua aplicação por e para qualquer país (OKEDIJI apud PASTOR: 15)

Finalmente, a proliferação de acordos bilaterais e regionais estabelecendo padrões mais elevados de proteção aos DPIs poderá levar à revisão dos níveis de proteção em negociações futuras na OMPI e na OMC. Bryan Mercurio (2006: 236) explica:

\footnotetext{
"Once countries negotiate enough bilateral/regional agreements with similar provisions, it becomes easier to manipulate multilateralism. In this regard, bilateralism naturally leads to multilateralism by creating common negotiating positions as well as through a 'laboratory effect' of trialling at the bilateral/regional level."
}

Essa dimensão global distingue o "novo bilateralismo", refletido nos acordos de livre comércio celebrados após o advento do Acordo TRIPS, do "velho bilateralismo", que, como visto anteriormente, inaugurou a fase internacional da proteção à propriedade intelectual. Enquanto o "velho bilateralismo" consistia em "an extraterritorial extension of intellectual property norms to developing, (and at times other developed countries), through the agency of treaty power" ou, em outras palavras, "an explicit instrument to inject domestic norms into international economic relations" como explica Okediji (20032004: 135-136), o "novo bilateralismo" destina-se a estabelecer novos padrões universais de proteção aos DPIs. Nesse sentido, "PTAs [acordos de preferências comerciais] bring IP [propriedade intelectual] much closer to actual harmonization" (SHADLEN, 2005: 11). 


\section{Considerações finais: a evolução do Regime Internacional da Propriedade Intelectual}

O histórico apresentado na Seção 3 evidencia dois importantes pontos de inflexão na evolução da proteção internacional à propriedade intelectual: a inauguração do período internacional, marcada pelo advento das Convenções de Paris e de Berna; e o início do período global, caracterizado pela emergência do Acordo TRIPS. A partir do instrumental teórico introduzido na primeira seção deste trabalho, nesta seção sustentaremos que esses dois pontos de inflexão correspondem, respectivamente, ao surgimento do Regime Internacional da Propriedade Intelectual (RIPI) e à mudança mais significativa por que passou esse regime até o momento.

Como vimos na primeira seção, a escola neoliberal (ou estrutural modificada) explica o surgimento dos regimes internacionais a partir do compartilhamento de interesses pelos Estados: nas situações em que a cooperação resulta em maiores ganhos para todos os atores, a tendência é que os Estados, agindo de forma egoísta e racional, optem pelo estabelecimento dos regimes internacionais.

Ao apontar por que os regimes internacionais podem tornar a ação dos Estados mais eficiente do que a celebração de acordos ad hoc, Robert Keohane (1982: 334-339) recorre às teorias econômicas a respeito das falhas de mercado, argumentando que a política mundial pode ser comparada a um mercado imperfeito. A função dos regimes internacionais seria amenizar essas imperfeições, assegurando que, por meio de uma coordenação eficiente, que reduza riscos e incertezas, os melhores resultados sejam alcançados, em benefício de todos os membros do regime. 
Podemos explicar o advento das Convenções de Paris e de Berna partindo dessa perspectiva. Para os grupos de países que levaram a cabo as duas iniciativas, o status da proteção internacional às invenções e criações de seus nacionais na segunda metade do século XIX era francamente insatisfatório, já que, como vimos na Seção 3, muitos países não protegiam DPIs originados no exterior, ou o faziam de forma insuficiente. Assim, eram grandes as chances de que os bens intelectuais, uma vez exportados, fossem alvo de cópia ou pirataria. Por sua vez, o risco elevado de surgimento de caronas tinha o efeito de desestimular, não apenas a criação, mas também o intercâmbio das mercadorias que incorporassem essas inovações. Em um momento em que o comércio internacional intensificava-se cada vez mais, essa deficiência induzia, do ponto de vista desses países, a uma situação sub-ótima em termos tanto de desenvolvimento, quanto de comercialização de bens intelectuais ${ }^{33}$.

Como vimos, a tentativa de solucionar esse impasse por meio de acordos bilaterais acabou introduzindo maior complexidade e insegurança jurídica ao sistema. Assim, agindo de forma egoísta e racional, e com vistas a reduzir os riscos e as incertezas, os Estados ofertantes de bens que incorporavam propriedade industrial ou direitos autorais partiram para a negociação de acordos multilaterais. Ao estabelecerem parâmetros normativos internacionais para a proteção aos DPIs, esses acordos deram origem ao Regime Internacional da Propriedade Intelectual (RIPI).

\footnotetext{
${ }^{33}$ A esse respeito, ver a caracterização da propriedade intelectual como bens público na seção 2.1.
} 
Parece-nos legítimo considerar que tratou-se, desde o início, de um único regime da propriedade intelectual - e não de dois regimes - um relativo à propriedade industrial, representado pela Convenção de Paris, e outro concernente aos direitos autorais, simbolizado pela Convenção de Berna. A justificativa para isso não se baseia apenas na unidade conceitual, ou ainda, na tendência histórica de consideração conjunta desses dois campos temáticos, ambos aspectos abordados na Seção 2.

A justificativa é também institucional e normativa. Institucional porque, embora tenham sido negociadas em paralelo, as Convenções de Paris e de Berna, concluídas respectivamente em 1883 e 1886, logo tiveram a sua administração reunida sob o mesmo “Bureaux Internationaux Réunis Pour la Protection de la Propriété Intelectuelle” (BIRPI), criado em 1892, e posteriormente pela OMPI. Normativa, em razão de as duas Convenções sustentarem-se em princípios compartilhados como o princípio da nação mais favorecida e o princípio do tratamento nacional, que ainda hoje integram o RIPI.

Por fim, consideramos que a formação desse regime foi condicionada por uma ordem negociada (que se contrapõe às ordens espontâneas ou impostas), já que, como demonstramos, o RIPI surgiu da "coordenação consciente e do consentimento explícito"34 dos atores envolvidos. Como é característico das ordens negociadas, o resultado dessa coordenação restou formalmente consolidado nas já mencionadas Convenções de Paris e de Berna, às quais se juntaram outros tratados na medida em que o RIPI foi-se desenvolvendo, sendo o mais relevante deles o Acordo TRIPS.

\footnotetext{
${ }^{34}$ Ver seção 1 deste trabalho.
} 
Vimos, na Seção 3 deste trabalho, que durante o período internacional foram negociadas e concluídas a Convenção de Paris, a Convenção de Berna e, além delas, uma série de outros acordos internacionais que regulamentaram diversos aspectos relativos à propriedade intelectual ${ }^{35}$.

As sucessivas revisões e emendas às Convenções de Paris e de Berna, bem como os dispositivos introduzidos pelos novos tratados, contribuíram à consolidação do RIPI. A partir deles, o RIPI adaptou-se a novas realidades - são exemplo disso as alterações introduzidas na Convenção de Berna pela Ata de Paris, que garantiram uma maior flexibilidade aos países em desenvolvimento. Além disso, novos aspectos foram introduzidos, notadamente de natureza procedimental, como aqueles relativos à classificação de marcas e desenhos industriais e ao registro internacional de marcas e patentes $^{36}$.

A consolidação deu-se também com um aumento significativo na adesão ao RIPI, que se acentuou a partir do fenômeno da descolonização, na segunda metade do século XX. Se as Convenções de Paris e de Berna contavam, à época da sua aprovação, com apenas 10 e 11 países signatários, em 1986 esse número havia subido para, respectivamente, 94 e 73 partes contratantes ${ }^{37}$.

De natureza incremental, essas transformações não alteraram o cerne do RIPI. É possível afirmar, portanto, nos termos da "definição consensual” proposta por Krasner, que

\footnotetext{
${ }^{35}$ Ver Tabela 1.

${ }^{36}$ Idem.

${ }^{37}$ Dados disponíveis nas páginas www.wipo.int/treaties/en/showresults.jsp?lang=en\&treaty id=2 e www.wipo.int/treaties/en/showresults.jsp?lang=en\&treaty_id=15, acessadas em 10 de março de 2008.
} 
elas atingiram apenas as regras e procedimentos do RIPI, sem modificarem substancialmente os seus princípios e normas: permaneceram os aspectos normativos centrais que haviam sido introduzidos com as Convenções de Paris e de Berna, como, por exemplo, os mais de uma vez mencionados princípios da nação mais favorecida e do tratamento nacional.

Com o Acordo TRIPS, o RIPI passou por transformações mais expressivas. A mais importante delas foi a introdução do tema da propriedade intelectual no âmbito da $\mathrm{OMC}$, em um movimento de "forum shifting" (BRAITHWAITE e DRAHOS apud HELFER, 2004: 14; OKENDIJI, 2003-2004: 141 e MORIN, 2003: 3).

A expansão para a $\mathrm{OMC}$ deu origem a três conseqüências principais. Em primeiro lugar, as disputas relativas ao Acordo passaram a submeter-se ao Órgão de Solução de Controvérsias daquela Organização, cujas decisões, caso descumpridas, poderiam ensejar retaliações comerciais, inclusive fora do âmbito da propriedade intelectual. Esse mecanismo é certamente mais eficaz quando comparado ao recurso à Corte Internacional de Justiça, procedimento previsto nas Convenções de Berna e Paris que, como vimos, nunca chegou a ser implementado.

Em segundo lugar, foram estabelecidos novos padrões mínimos de proteção às diferentes categorias de direito de propriedade intelectual, mais elevados se comparados aos que vigiam no RIPI antes da entrada em vigor do Acordo TRIPS. Tornou-se obrigatória, por exemplo, a concessão de direitos patentários para produtos alimentícios e farmacêuticos. 
Em terceiro lugar, a introdução do tema na OMC fez com que a adesão ao RIPI atingisse patamares ainda mais elevados que os alcançados durante o período internacional. Com efeito, passaram a ser obrigatórios para todos os atualmente mais de 150 membros da OMC não apenas os direitos e obrigações instituídos pelo Acordo TRIPS, mas também porção substancial dos dispositivos normativos previstos em tratados anteriores, que foram incorporados ao Acordo TRIPS por referência ${ }^{38}$.

Nesse sentido, é interessante notar como o já crescente número de Partes Contratantes das Convenções de Paris e de Berna deu um salto significativo a partir do lançamento da Rodada Uruguai (que, em 1986, estabeleceu o mandato negociador para o Acordo TRIPS): desde então, 78 novas Partes aderiram à CUP, enquanto nada menos que 90 aderiram à Convenção de Berna.

Embora significativas, as mudanças introduzidas no RIPI em decorrência do Acordo TRIPS não resultaram em alterações revolucionárias; em outras palavras, não modificaram os princípios e normas que compõem o núcleo do Regime. Ao contrário, esses princípios e normas foram fortalecidos com as novas regras (como a obrigatoriedade de patenteamento de produtos farmacêuticos e alimentos) e procedimentos (como o mecanismo de solução de controvérsias) previstos no Acordo TRIPS. O RIPI tornou-se ainda mais robusto, e também mais eficaz.

\footnotetext{
${ }^{38}$ Ver, por exemplo, o Acordo TRIPS, Artigo 2: "Com relação às Partes II, III e IV deste Acordo, os Membros cumprirão o disposto nos Artigos 1 a 12, e 19, da Convenção de Paris (1967)"
} 
Como vimos, um elemento marcante das negociações que culminaram no Acordo TRIPS foi o emprego, pelos países desenvolvidos, de instrumentos como mecanismos unilaterais de pressão e a promessa de acesso a mercados, como forma de persuadir os países em desenvolvimento a aceitar os termos do Acordo. Isso foi necessário porque, considerado isoladamente, o Acordo TRIPS não era considerado pela maior parte países em desenvolvimento como vantajoso.

Não lhes interessava fortalecer a proteção aos DPIs, mas sim garantir a manutenção de flexibilidades que lhes permitissem adotar políticas públicas visando ao seu desenvolvimento tecnológico, econômico e social. Essa foi uma diferença importante entre as negociações do Acordo TRIPS e as negociações para as Convenções de Paris e de Berna. Por envolverem um conjunto muito maior de atores, grande parte deles importadora líquida de bens intelectuais, as discussões sobre propriedade intelectual no GATT/OMC envolviam um compartilhamento muito menor de interesses, e resultaram em uma distribuição dos benefícios bem mais desigual, do que as negociações anteriores sobre a matéria.

A esse respeito, Oran Young (1982: 284) contrapõe os regimes impostos aos regimes negociados, conceituando aqueles como "deliberately established by dominant actors who succeed in getting others to conform to the requirements of these orders through some combination of coercion, cooptation, and the manipulation of incentives". Por esse ponto de vista, as negociações que culminaram no Acordo TRIPS poderiam ser entendidas como tendo ocorrido em uma ordem imposta, circunstância diferente, portanto, daquela em que o RIPI foi originalmente formulado, em uma ordem claramente negociada. 
No entanto, Robert Keohane (1982: 330) ensina que os regimes internacionais são sempre condicionados por constrangimentos impostos pelos atores que detêm maior poder, o que não implica que os países mais fracos deixem de exercer voluntariamente as suas escolhas: "[w]eak actors as well as more powerful actors make choices, even if they make them within more severe constraints" (1982: 332). Nesse sentido, não haveria regime completamente imposto, sem qualquer tomada de decisão por parte de todos os atores, nem regime completamente negociado, sem qualquer imposição de constrangimento.

De qualquer modo, admitimos que as mudanças que resultaram da entrada em vigor do Acordo TRIPS foram mudanças no RIPI, e não do RIPI. Assim como nas transformações anteriores, entendemos que elas responderam a alterações estruturais na economia internacional. $\mathrm{Na}$ hipótese mais recente, essa mudança estrutural teria sido um crescimento substancial no mercado de bens intelectuais, de que os países desenvolvidos, notadamente os Estados Unidos, são os maiores ofertantes: "there is no doubt that recent decades have seen a marked growth in that market, as economies of the advanced nations shifted from 'industrial' economies to 'information' economies. That growth" complementa o autor, fazendo referência aos diferentes interesses envolvidos nessa discussão internacional, "increased the potential economic rents from intellectual property rights and so may have increased the asymmetry of incentives (...) between supporters and opponents of expanded intellectual property rights" (LANDES e POSNER, 2004: 25).

A disciplina da propriedade intelectual vem passando por novas transformações no mundo pós-Acordo TRIPS, com a proliferação de acordos bilaterais e regionais que abrangem a matéria. Conquanto ainda não esteja claro de que forma esse novo quadro 
normativo será incorporado ao RIPI, o conteúdo dos novos acordos indica que, mais uma vez, não se tratará de uma mudança revolucionária do Regime, mas sim de um fenômeno meramente evolucionário. Ao que tudo indica, o RIPI incorporará novas regras e procedimentos que resultarão em uma proteção ainda maior dos DPIs, seguindo a tendência observada desde o seu surgimento. 


\section{REFERÊNCIAS BIBLIOGRÁFICAS}

ABBOTT, Frederick M. Toward a new era of objective assessment in the field of TRIPS and variable geometry for the preservation of multilateralism. Journal of International Economic Law, Oxford University Press, v. 8, n. 1, 2005, p. 77-100.

ARAÚJO FILHO, José Carlos C. A Agenda para o Desenvolvimento na Organização Mundial da Propriedade Intelectual. Monografia apresentada como requisito parcial para a obtenção do título de Especialista em Relações Internacionais. UnB. Brasília: abril de 2007.

ARSLANIAN, Regis P. O recurso à Seção 301 da legislação de comércio norte-americana e a aplicação de seus dispositivos contra o Brasil. Instituto Rio Branco. Brasília: 1994.

CEPALUNI, Gabriel. Regime de patentes: Brasil x Estados Unidos no tabuleiro internacional. Lex Editora. São Paulo: 2006.

CEPALUNI, Gabriel. Regimes internacionais e o contencioso das patentes para medicamentos: estratégias para países em desenvolvimento. Contexto Internacional, v. 27, $\mathrm{n}^{\mathrm{o}} 1$, jan-jun 2005, p. 51-99.

Comission on Intellectual Property Rights (CIPR). Integrating intellectual property rights and development policy. Londres: 2002.

CORREA, Carlos M. Bilateral investment agreements: agents of new global standards for the protection of intellectual property rights? Disponível em

http://www.grain.org/briefings/?id=186. Acessado em 10 de março de 2008.

CORREA, Carlos M.; YUSUF, Abdulqawi A. Introduction. In CORREA, Carlos M. e YUSUF, Abdulqawi A. (eds.). Intellectual property and internacional trade - the TRIPS Agreement. Kluwer Law International. Londres: 1998, p. xvii-xx.

DRAHOS, Peter. An alternative framework for the global regulation of intellectual property rights. Centre for Governance of Knowledge and Development. Working Paper: outubro 2005. Disponível em http://cgkd.anu.edu.au/menus/workingpapers.php. Acessado em 10 de março de 2008.

DRAHOS, Peter. The regulation of public goods. Journal of International Economic Law. Oxford University Press, v. 7, nº 2, 321-339, 2004.

DRAHOS, Peter. The universality of intellectual property rights: origins and development. Texto apresentado na discussão em comemoração do $50^{\circ}$ aniversário da Declaração Universal dos Direitos Humanos (Genebra, 9 de novembro de 1998). Disponível em http://www.wipo.int/tk/en/hr/paneldiscussion/papers/pdf/drahos.pdf. Acessado em $10 \mathrm{de}$ março de 2008. 
HASENCLEVER, Andreas; MAYER, Peter; RITTBERGER, Volker. Theories of International Regimes. Cambridge: University Press, 1997.

HASENCLEVER, Andreas; et alii. Interests Power, Knowledge: The study of International Regimes. International Organization. Vol 40, nº 2 (Mershon International Studies Review), 1996, p. 177-228.

KEOHANE, Robert O. The Demand for International Regimes. International Organization. Vol 36, nº 2 (International Regimes), 1982, p. 325-355.

KEOHANE, Robert O.; NYE, Joseph S. Power and Interdependence. 3 ed. Nova Iorque: Longman, 2001.

KEOHANE, Robert. O.; NYE Jr., Joseph S. Introduction. MIMEO. P. 1-41

KRASNER, Stephen. Sovereignty: organized hypocrizy. Princeton: Princeton University Press, 1999.

KRASNER, Stephen. Structural Causes and Regime Consequences: Regimes as Intervening Variables. International Organization. Vol 36, no 2 (International Regimes), 1982, p. 185-205.

LANDES, William M.; POSNER, Richard A. The political economy of intellectual property law. AEI-Brookings Joint Center for Regulatory Studies. Washington: 2004.

MANKIW, N. Gregory. Introdução à economia. São Paulo: Thompson Learning, 2007. Cap. 11: Bens públicos e recursos comuns, p. 223-239.

MAY, Christopher. Social limits to the commodification of knowledge: ten years of TRIPs (Review Essay). Journal of Institutional Economics, Cambridge University Press, v. 2, $\mathrm{n}^{\mathrm{o}} 1$, 2006, p. 91-108.

MERCURIO, Bryan. TRIPS-Plus Provisions in FTAs: Recent Trends. In BARTELS, Lorand; ORTINO, Federico (eds.). Regional Trade Agreements and the WTO Legal System. Oxford University Press, 2006, p. 215-237.

MORIN, Jean-Frédéric. The bilateral IP agreements. Texto apresentado na conferência internacional "Moving forward from Cancun - The Global Governance of Trade, Environment and Sustainable Development" (Berlim, 30-31 de outubro de 2003), promovida pelo Institute for International and European Environmental Policy (Ecologic). Disponível em http://www.ecologic-events.de/Cat-E/en/documents/morin.pdf. Acessado em 10 de março de 2008.

MOSER, Petra. How do patents influence innovation? Evidence from nineteenth-century world's fairs. The American Economic Review, American Economic Association, v. 95, $\mathrm{n}^{\mathrm{o}}$ 4, set 2005, p. 1214-1236. 
OKENDIJI, Ruth L. Back to Bilateralism? Pendulum Swings in International Intellectual Property Protection. University of Ottawa Law and Technology Journal. 2003-2004, p. 125-147.

Organização Mundial da Propriedade Intelectual (OMPI). WIPO Intellectual Property Handbook: policy, law and use. Genebra: 2004. Disponível em http://www.wipo.int/aboutip/en/iprm/index.html. Acessado em 10 de março de 2008.

Organização para a Cooperação Econômica e o Desenvolvimento (OCDE). Patents and innovation: trends and policy challenges. OECD Publications. Paris: 2004. Disponível em http://www.oecd.org/dataoecd/48/12/24508541.pdf. Acessado em 10 de março de 2008.

PASTOR, Rafael. The impact of free trade agreements on intellectual property standards in a post-TRIPS World. Disponível em http://www.bilaterals.org/article.php3!id_article=4311. Acessado em 10 de março de 2008.

PERELMAN, Michael. The political economy of intellectual property. Monthly Review, V. 54, $\mathrm{n}^{\mathrm{o}} 8$, jan 2003, p. 29-37.

SHADLEN, Ken. Policy Space for Development in the WTO and Beyond: The Case of Intellectual Property Rights. Global Development and Environment Institute. Working Paper N. 05-06. Nov 2005.

SHAFFER, Gregory. Recognising public goods in WTO dispute settlement: who participates? Who decides? The case of TRIPS and pharmaceutical patent protection. Journal of International Economic Law. Oxford University Press, v. 7, nº 2, 2004, p. 459482.

STRANGE, Susan. Cave! Hic dragones: a critique of regime análisis. International Organization. Massachussetts Institute of Technology, v. 36, n 2 (International Regimes), 1982, p. 479-496.

STRAUS, Joseph. The impact of the new world order on economic development: the role of the intellectual property system. European Review, vol. 15, No 1, 2007, p. 47-63.

VIVAS-EUGUI, David. Regional and bilateral agreements and a TRIPS-plus world: the Free Trade Area of the Americas (FTAA). Trips Issues Papers. Quaker United Nations Office (QUNO), Genebra. 2003.

YOUNG, Oran. Governance in World Affairs. Ithaca: Cornell University Press, 1999.

YOUNG, Oran. Regime Dynamics: The Rise and Fall of International Regimes. International Organization. Vol 36, nº 2 (International Regimes), 1982, p. 277-297.

YUSUF, Abdulqawi A. TRIPS: background, principles and general provisions. In CORREA, Carlos M.; YUSUF, Abdulqawi A. (eds.). Intellectual property and 
internacional trade - the TRIPS Agreement. Kluwer Law International. Londres: 1998, p. 322. 